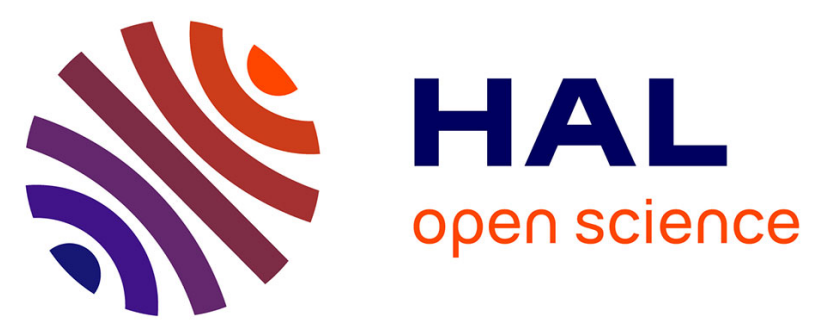

\title{
Extensive investigation of the ultrastructure of kink-bands in flax fibres
}

Alessia Melelli, Sylvie Durand, Olivier Arnould, Emmanuelle Richely, Sofiane Guessasma, Frédéric Jamme, Johnny Beaugrand, Alain Bourmaud

\section{- To cite this version:}

Alessia Melelli, Sylvie Durand, Olivier Arnould, Emmanuelle Richely, Sofiane Guessasma, et al.. Extensive investigation of the ultrastructure of kink-bands in flax fibres. Industrial Crops and Products, 2021, 164, pp.113368. 10.1016/j.indcrop.2021.113368 . hal-03170573

\section{HAL Id: hal-03170573 \\ https://hal.science/hal-03170573}

Submitted on 16 Mar 2021

HAL is a multi-disciplinary open access archive for the deposit and dissemination of scientific research documents, whether they are published or not. The documents may come from teaching and research institutions in France or abroad, or from public or private research centers.
L'archive ouverte pluridisciplinaire HAL, est destinée au dépôt et à la diffusion de documents scientifiques de niveau recherche, publiés ou non, émanant des établissements d'enseignement et de recherche français ou étrangers, des laboratoires publics ou privés.

\section{(ㅇ)(1) $\$$}

Distributed under a Creative Commons Attribution - NonCommercial - NoDerivatives| 4.0 


\title{
Extensive investigation of the ultrastructure of kink-bands in flax fibres
}

\author{
Alessia Melelli ${ }^{1}$, Sylvie Durand ${ }^{2}$, Olivier Arnould ${ }^{3}$, Emmanuelle Richely $^{2}$, Sofiane \\ Guessasma $^{2}$, Frédéric Jamme ${ }^{4}$, Johnny Beaugrand ${ }^{2}$, Alain Bourmaud ${ }^{1}$
}

\author{
${ }^{1}$ Univ. Bretagne Sud, UMR CNRS 6027, IRDL, Lorient, France \\ ${ }^{2}$ UR1268 Biopolymères Interactions Assemblages, INRAE, Nantes, France \\ ${ }^{3}$ LMGC, Université de Montpellier, CNRS, Montpellier, France \\ ${ }^{4}$ Synchrotron SOLEIL, DISCO beamline, Gif-sur-Yvette, France \\ Corresponding author: alain.bourmaud@univ-ubs.fr
}

\begin{abstract}
Fibres from annual plants are a sustainable alternative for glass fibres in composite manufacturing. However, both synthetic fibres, such as carbon fibres, and cellulosic fibres exhibit heterogeneities along their lengths, which appeared as localized morphological disorientations known as kink-bands. In plant fibres, kink-bands occur due to growing conditions under abiotic stress, during the retting stage and the fibre extraction process. Many studies have been conducted to identify the origin of such kink-bands and their impact on the mechanical behaviour of composites but their characteristics and fine ultrastructure remain unclear. Presence of cavities in transition zones was assessed by SEM and AFM and confirmed by low intensity SHG signal, especially when large size kink-bands are considered. Moreover, transverse indentation modulus is obtained by AFM in Peak force mode; no substantial differences were observed between the kink-band and defect-free regions with average values ranging from 6.2 to $7.3 \mathrm{GPa}$. Also, important MFA changes are
\end{abstract}


measured through SHG imaging, especially in large kink-bands with local misorientation up to $47^{\circ}$. Thus, this intense investigation of kink-band areas reveals ultrastructure heterogeneities and the presence of local defects.

Keywords: Flax fibres; Kink-band; SHG; AFM; Microfibrillar angle; Mechanical properties

\section{Introduction}

Composites are often considered to be materials of the future, owing to their highperformance mechanical properties, low weight and applicability in several domains, from buildings to automotive or sport and leisure fields (Mohanty et al., 2018). To design ecofriendly composite materials, plant fibres, and especially hemp and flax in Europe, have attracted attention as renewable, biodegradable and cost-effective resources (Le Duigou et al., 2011; Deyholos and Potter, 2014; Pil et al., 2016). Nevertheless, they exhibit certain limitations compared to synthetic fibres (Madsen and Gamstedt, 2013; Deyholos and Potter, 2014). Moreover, the mechanical properties of plant fibres are dependent on the plant growing conditions and on the overall agricultural and mechanical extraction process (harvesting time, retting, scutching, hackling etc.) where decortication step has the main impact.

More specifically, the living plant is subjected to certain abiotic stress when growing, such as those related to wind conditions or dried soils, which can favour deformations and damages on the fibres (Hughes et al., 2000; Thygesen and Asgharipour, 2008). Additional defects are also introduced during the retting and scutching process (Nodder, 1922; Hughes et al., 2000; Thuault et al., 2013; Zeng et al., 2015; Hernandez-Estrada et al., 2016). Such defects appear under the optical microscope as local morphological deformations along the entire length of the cell, and they are commonly termed as kink-bands, defects or dislocations, although 
several other terms have been used in the literature; a list of these terms can be found in (Nyholm et al., 2001). In the present work, we choose to use the term "kink-band".

Flax fibres have a hierarchical structure consisting of different layers: the primary cell wall (PCW) is the outermost layer of the fibre and the secondary cell wall is divided into three sublayers, often called S1, S2 and S3 in the field of plant fibres composite materials, among which the $\mathrm{S} 2$ is the thickest one and also the main responsible of the longitudinal mechanical properties of the fibres. In the present paper, according to the poorly lignified and gelatinous character, as well as to the low MFA of flax secondary cell walls (Melelli et al., 2020), we choose to call the different layers of the secondary wall (from the compound middle lamella to the lumen) S1, G and $\mathrm{Gn}$, based on precise descriptions in the literature (Clair et al., 2018; Gorshkova et al., 2018). In the centre of a single elementary fibre, a lumen is present as an empty cavity, whose diameter depends on the botanical species, variety, maturity and location along the plant stem (Bourmaud et al., 2018). These layers differ from each other in terms of the chemical composition and cellulose microfibril orientation (Baley et al., 2018). The microfibril angle (MFA) is defined as the angle between the cellulose microfibrils and the fibre axis and has been generally reported to be approximately $8^{\circ}$ in the $G$ layer of flax (Bourmaud et al., 2013). However, observations through second harmonic generation (SHG) microscopy technique demonstrated that the MFA of flax G layer varies between $0^{\circ}$ and $7^{\circ}$, depending on the area examined (Melelli et al., 2020). Experimentally speaking, when SHG, scanning electron (SEM) or atomic force microscopy (AFM) are used, the observed angle does not directly correspond to the angle measured in microfibrils themselves but rather to the angle between the fibre axis and a bundle of microfibrils, i.e. a macrofibril, with diameter from 14 to 200 nm (Fahlén and Salmén, 2003; Balnois et al., 2007; Donaldson, 2007). Indeed, in biology, a microfibril corresponds to several glucan chains (18-40 units) and to a diameter ranging from 2 to $4 \mathrm{~nm}$ (Donaldson, 2007; Lyczakowski et al., 2019) estimated in a relevant way only by more in-depth investigative methods such as Nuclear Magnetic Resonance (NMR) (Bourmaud et al., 2019b). 
This well-defined and ordered hierarchical structure present in flax cells can however be modified when kink-bands occur. The inner structure of a kink-band in plant fibres has not been clarified yet. Thygesen and Gerlinger demonstrated that kink-bands exhibited the same chemical composition as in the homogeneous areas of the hemp fibres (Thygesen and Gierlinger, 2013); however, around the largest kink-bands, transition areas were observed, in which the cellulose orientation was modified, and thus, the microfibrils were less oriented. The same authors also estimated that the MFA within and at the periphery of the kink-band in hemp was $30^{\circ}$ and $10^{\circ}-15^{\circ}$, respectively (Thygesen and Gierlinger, 2013).

The evolution of kink-band areas behaviour and structure during a mechanical loading has also been explored by various research groups. By using polarised light microscopy, Thygesen et al. have evidenced a disappearance of kink-band areas on hemp fibre, by realignment and straightening of macrofibrils under tensile loading (Thygesen et al., 2007). Another team developed numerical modelling of cellulose microfibrils with local misorientation under tensile loading and showed a slight realignment of dislocated chains after a specific strain in kink-band region, but without leading to the full recrystallization of the dislocated regions (Khodayari et al., 2020). Generally, the presence of significant kink-bands corresponds to a lower tensile strength inside the fibres, because kink-bands are weak points at which the cracks begin to propagate until the elementary fibre breaks during tensile testing (Baley, 2004; Thygesen et al., 2007; Aslan et al., 2011; Beaugrand et al., 2017). Aslan et al. (2011) hypothesised that the fractures were initiated in the outer layer of the region with the largest kink-band and subsequently propagated inside the cell wall until they reached the nearest small kink-band. Using a focused ion beam-scanning electron microscope (FIBSEM), Zhang et al. observed that the kink-band regions in flax fibres were consisting of a main cavity composed of several voids assembled and separated by membranes. Moreover, small pores were regrouped in the area close to the kink-band, and this phenomenon did not occur in other areas of the fibre (Zhang et al., 2015). 
The influence of the kink-bands is also demonstrated when fibres are used in biocomposites, as the kink-band geometry renders a single fibre strongly inhomogeneous. During mechanical testing, for example, stress concentration occurs in these areas, resulting in fibre-matrix debonding and matrix micro-cracking (Hughes et al., 2000), and Le Duc et al. also demonstrated a sensitivity of the kink-band regions when flax fibres are compounded with a thermoplastic matrix (Le Duc et al., 2011). The overall weakness of flax kink-bands was numerically confirmed by Sliseris et al. in both cases, at both the isolated bundle and the composite scale (Sliseris et al., 2016). This negative effect of kink-bands on plant fibres and associated composite materials properties leads to a research path that aims at avoiding the formation of kink-bands by improving the fibre decortication process and investigating new extraction methods, such as the use of aqueous ammonia (Zeng et al., 2015). In parallel, the nature of kink-bands has been studied to describe the physical mechanism at their origin (Nilsson and Gustafsson, 2007; Benabou, 2008) and to artificially reproduce these bands by subjecting the fibres to bending or compression loads (Baley, 2004; Eder et al., 2008).

Despite all this research, only limited data are available in the literature on the internal ultrastructure or internal mechanical properties of the cell walls involved in kink-bands, and for this reason, an extensive investigation of the mechanical properties and the internal ultrastructure of these specific regions is necessary. Therefore, in this work, a range of kinkbands of flax fibres, representing 8 bundles and 12 single fibres, were examined with the main objective to provide additional and more in-depth information by using two cutting-edge investigation methods: i) AFM in Peak force quantitative nanomechanical mapping mode (AMF PF-QNM), to investigate the indentation modulus in kink-band regions at a micro-scale level, and, ii) the second harmonic generation microscopy at polarised controlled light (PSHG), to explore the MFA and ultrastructural changes in kink-bands areas. In addition, SEM micrographs were acquired to obtain complementary information.

\section{Materials and methods}




\subsection{Flax fibres}

Flax fibres of the Bolchoï textile variety, organoleptic classification number 66233, cultivated in 2018, Normandy, France, by the Depestele group, were retted for 6 weeks and then mechanically scutched.

\subsection{Methods}

\section{- SEM}

A fibre bundle with a thickness of a few millimetres was extracted and glued on the sample holder by using a conductive carbon tape. A thin gold-sputter coating was performed for $180 \mathrm{~s}$ by using an Edwards Scancoat Six device, and the sample was successively scanned using a Jeol JSM 6460LV scanning electron microscope. Furthermore, observations on other flax bundles were carried out after cryofracturing; to induce cryofracturing, several flax bundles, different from those used in AFM and SHG, were embedded in agar resin (epoxy resin agar low viscosity resin (LV); Agar scientific UK) and placed in an oven at $60^{\circ} \mathrm{C}$ overnight to ensure complete polymerisation. Subsequently, the blocks were frozen in liquid nitrogen and mechanically broken using hand pliers, fibres being here submitted to a pull-out phenomenon. The broken sections were successively gold sputtered and investigated.

$$
\text { - SHG }
$$

In order to perform investigations using the SHG microscopy technique, flax single fibres and bundles were extracted from the Bolchoï fibre batch and mounted on paper support according to ASTM C1557. The paper support was mounted between two coverslips to acquire the SHG images. These fibre elements are different from those used for SEM and AFM imaging and are used without any resin embedding, but they are both extracted from the same flax batch. 8 different single fibres and 3 bundles were studied by SHG in the present work.

A multiphoton Nikon A1 MP+ microscope (NIKON, France) was equipped with a long working distance (LWD) 16x (NA 0.80) water immersion objective (NIKON, France), a tuneable Mai 
Tai XF mode-5 locked Ti:sapphire femtosecond laser (SPECTRA PHYSICS, France) and a half-wave plate (HWP) (MKS-Newport, USA) placed in front of the laser excitation beam. At the excitation wavelength of $810 \mathrm{~nm}$, the average laser power was $1.5 \mathrm{~W}$, and only $5 \%$ of the power was used to scan the flax fibres in order to avoid tissues damage and photobleaching. Both the backward and forward signals were collected with three band pass filters at 460/60 nm (autofluorescence), 550/88 nm (autofluorescence) and 406/15 nm (SHG signal). The GaAsP NDD (gallium arsenide non-descanned) detectors were used. The scan line average was 8 , the scan velocity was fixed as 1 (fps) and the scan size was $512 \times 512$ pixels. Prior to each acquisition, the half wave plate (HWP) was set parallel to the fibre axis, following Melelli et al. (2020). Several images in air were acquired before adding distilled water between the two coverslips with a pipette and waiting for 5 min to saturate the fibres. The NIS elements (NIKON, France) software was used to set the parameters of the multiphoton microscope and collect the data. ImageJ software (National Institute of Health, USA) (Schneider et al., 2012) was used to analyse the data.

\section{- $\quad$ AFM in PF-QNM mode}

\section{Sample preparation}

To perform the atomic force microscopy examination, another set of bundles were placed in an oven for two hours at $60^{\circ} \mathrm{C}$, in order to dry the sample without ethanol and thus limit embedding resin penetration (Coste et al., 2021), while the agar resin was prepared in a "soft" mixture, as described in its technical documentation (epoxy resin agar low viscosity resin (LV); Agar scientific UK). Subsequently, the flax bundles were cut to have a length of less than $5 \mathrm{~mm}$ and placed in a flat silicone embedding mould (Polysciences) in the transverse direction, and the surface was prepared by cutting several flax fibres along their length to highlight the inner structure. 
Figure 1

As illustrated in Figure 1, different bundles of flax fibres were embedded in epoxy resin, and the block was placed in an oven at $60^{\circ} \mathrm{C}$ overnight to realise the final polymerisation. It was successively reduced in thickness to attain a final height of approximately $4 \mathrm{~mm}$ and glued on a $12 \mathrm{~mm}$ AFM stainless steel mounting disc. The sample surface was cut using an ultramicrotome (Ultracut S, Leica Microsystems SAS, France) equipped with diamond knives (Histo and Ultra AFM, Diatome, Switzerland) to obtain thin sections (final thickness of approximately $50 \mathrm{~nm})$ at a reduced cutting speed $(\sim 1 \mathrm{~mm} / \mathrm{s})$, to minimise the compression and sample deformation during the cutting process, and thereby reduce the sample surface damage and topography modification.

\section{$\underline{\text { AFM measurements }}$}

A Multimode 8 atomic force microscope (Bruker, Billerica, Massachusetts, USA) was equipped with a RTESPA-525 probe (Bruker probes, Billerica, Massachusetts USA). The average normal spring constant ranged between 147 and $203 \mathrm{~N} / \mathrm{m}$, calculated using the Sader method (https://sadermethod.org/), and the resonance frequency was approximately $525 \mathrm{kHz}$. The cantilever deflection sensitivity was calibrated on sapphire as a hard material. To reduce the process time, the relative method was applied to calibrate the tip radius, and Aramid fibres K305 Kevlar 21 Taffetas $305 \mathrm{~g} / \mathrm{m}^{2}$ (Sicomin epoxy systems-France), embedded in agar resin (agar low viscosity resin (LV); Agar Scientific, UK) with the same protocol as that used for the flax fibres, were chosen as standard materials for the calibration of the tip radius (Arnould et al., 2017). Their indentation modulus was previously measured by nanoindentation ( $24.3 \mathrm{GPa}$ and $5.4 \mathrm{GPa}$ for the centre of aramid fibres and embedded resin, respectively). The obtained tip radius ranged between 40 and $55 \mathrm{~nm}$. 
The fast scan axis angle was set at $90^{\circ}$, the maximum peak force setpoint was $200 \mathrm{nN}$ and the oscillation frequency was $2 \mathrm{kHz}$. The maximum fast scan velocity was set at $8 \mu \mathrm{m} / \mathrm{s}$, and the image resolution was $512 \times 512$ pixels. The gain was set in the automatic mode.

Different kink-bands areas of the fibres were accurately selected and investigated; to design the distribution figures of the indentation modulus (IM), data were calculated for each AFM force curves, representing between 3,300 and 16,700 points for each image analysed.

\section{Results and discussion}

3.1. SEM results in the kink-band area

The surface of a bundle of flax fibres was initially analysed using the SEM technique; first, it is necessary to define vocabulary and type of kink-bands we investigated here. In the fibre bundle, kink-bands were present in the entire group of fibres and appeared as a single continuous deficient area (Fig.2.a, b), as already reported in the literature (Madsen et al., 2016; Beaugrand et al., 2017). In (Nyholm et al., 2001), a fine description of the most common forms of kink-bands is listed; schemes of the kink-band region in a flax fibre bundle and elementary flax fibres are depicted in Figures 2.c and 2.d, respectively. In the present work, we have chosen to differentiate kink-bands according to their size using the terms type A (TA) and type B (TB) for the most and least pronounced, respectively.

Figure 2

Then, local structure and defects in each kind of kink-band are deeply investigated by SEM; SEM observations of peeled and cryo-fractured flax fibres and bundles are shown in Figure 3. The significant differences into the organization and orientation of the cellulose macrofibrils network showed in Figs.3.c, $d$ and e could suggest that different layers of the 
fibre are exposed. This observation allowed us to hypothesize a distinction of the visible layers by identifying them as primary cell wall (PCW), S1 and G. Indeed, the pattern of the surface of the $\mathrm{G}$ appeared to have a highly ordered structure, and this is in agreement with the one defined using almost all the existing models (Baley et al., 2018). Regarding S1, several studies reported the presence of a crisscrossed network of cellulose microfibrils at a significant angle to the axis (Wang et al., 2018; Bourmaud et al., 2019b), and the images obtained in (Zhang et al., 2015) by using the FIB-SEM also suggested the presence of a layer with a similar pattern, although each pattern was not attributed to a corresponding layer. This crisscrossed cellulose network in the layer expected to correspond to arguably S1 was less visible in the micrograph obtained in the present work, although it is clearly observable that cellulose orientation is not homogenous (Fig.3.c) or even in the opposite direction (Fig.3.d) than that observed in G layer (Fig.3.e). Nevertheless, both the layers of the secondary wall exhibited a deviation in the orientation of their macrofibrils in the kink-band region. This deviation occurred with a well-defined angle, following the shape of the kinkband (Fig. 3.b); it is clearly visible in Fig.3.e with a significant local orientation change for G layer macrofibrils.

Figure 3

Fig. 3.h shows a typical flax fibre after a cryo fracture process, with the innermost cell wall layers exposed and the lumen (white arrow) clearly observable. The main advantage of investigating cryo-fractured fibres is that the deformation of the fibres is limited and allows to examine sections with a clean break. We also noted that fractures owing to the cryofracture process often occur in the kink-band region, indicating that kinks are the weakest areas of the fibres. Hence, we focused on TA (Fig.3.f) and TB (Fig.3.g) kink-bands and Fig 3.i and k show corresponding inner layers of the flax cells where the areas selected are the regions at higher magnification illustrated in Figs 3.j and I, respectively. In general, all the macrofibrils 
were highly deviated following the shape of the kink, and all the layers were involved up to the lumen in both TA and TB kink-bands. Fig. 3.j highlights that certain macrofibrils were detached and less deviated than others, thereby creating cavities (see red arrows) between them and the other bundles of macrofibrils. These cavities are numerous and detectable in the largest TA kink-bands. On the other hand, inside the TB kink-band illustrated in Fig.3.I, one can notice a poor number of cavities, probably due to the less drastic deviation of the macrofibrils to their natural angle.

The impact of the preparation mode and the original existence of these cavities can be debated; in order to better understand the internal architecture of kink-bands regions and provide matching elements, the following sections aim to explore these areas by SHG and AFM microscopies.

3.2. Multiphoton study of the cellulosic kink-band architecture Multiphoton microscopy is used to deeply investigate the organisation of cellulose macrofibrils within kink-bands area; two different elementary flax fibres were analysed by multiphoton microscopy in air and water environment; resulting images are shown in Figure 4. Autofluorescence and SHG channels were separated to better examine the results obtained and both autofluorescence and second harmonic signals are visible in the two environments.

In air, the microfibril angle of the cellulose macrofibrils appears to be interrupted in the kinkband area and emits a lower second harmonic signal, which suggests a lower cellulose organisation compared to that in the area of the fibres free of defects, in line with the investigations conducted by other teams (Dai and Fan, 2011; Thygesen and Gierlinger, 2013). The SHG strongly depends on the polarisation angle of the laser and various SHG signals in the kink-bands can be collected by changing the polarisation angle with the HWP; however, the detected signals are lower than that in the remaining part of the fibre. 
Few studies have examined the impact of moisture on the structure and mechanical behaviour of elementary plant bast fibres; in fact, the hygroscopicity has been principally studied only when plant fibres are used in composites to characterise the final product (Célino et al., 2014a). Using the small-angle X-ray diffraction technique, Astley and Donald noted that the MFA in flax fibres increased from $11^{\circ}$ in a dry state to $15^{\circ}$ in a wet state (Astley and Donald, 2001).

In our case (Fig.4.a), one can argue there is a difference in contrast between the kink-band region and the rest of the fibre. In the water environment, the dark area between the kinkband and defect-free areas was less contrasted than that previously observed in air.

Figure 4

Toba et al. and Célino et al. examined fibre bundles (wood and flax, hemp and sisal) through $\mathrm{XRD}$ and Fourier transform infrared spectroscopy in attenuated total reflectance mode (FTIRATR) (Toba et al., 2013; Célino et al., 2014b). In both of these studies, the authors first examined the wet samples and successively the dehydrated state and they found that the crystallinity increased owing to the sorption of water. This increment in the crystallinity linked with the sorbed water was also observed by Nakamura et al., who examined cotton by using differential scanning calorimetry and XRD (Nakamura et al., 1983). Nakamura et al. (1983), followed by Célino et al. (2014b), suggested that the amorphous phase of the cellulose likely became more crystalline with moisture. The increase in the crystallinity when the fibres were in a wet state likely occurred due to the hydrogen bonds that water formed with cellulose or hemicellulose, which broke after the dehydration, thereby causing a relaxation of the cellulose structure and a consequent decrease in the crystallinity. The SHG observations in the kink-bands areas support the hypothesis that an amorphous region may evolve towards a more crystalline region after wetting, resulting in a more ordered structure that led to the collection of a higher SHG signal corresponding to a lower contrast (with the remaining fibre). However, a second hypothesis for the smaller difference 
in contrast when considering the fibres mounted in water is a partial re-organization of the macrofibril network, which was previously disoriented during the formation of the kink-band, due to the swelling of the fibre.

In Figure 4.b, the SHG was used to analyse a bundle consisting of three elementary fibres, two of them visible in the foreground and the third one hidden by the two, mounted in water. Here 4 images along the Z-axis were acquired with a step of $8 \mu \mathrm{m}$. Measurements were recorded in water. Different macrofibrils orientations in the SHG channel, along with the lumen $+\mathrm{Gn}$ layer on the autofluorescence channels can be observed. On both foreground fibres, the lumen appears progressively, approximately in the middle plane of the fibre. This latter phenomenon is highly visible due to the autofluorescence channels in blue/cyan (R460/60 and T460/60) and magenta (R550/88 and T550/88 TNDD), which highlight the Gn layer around the lumen that follows the shape of the kink-band. This fluorescent signal is attributed to the remaining cytosolic fluorescent components or cytochrome components liberated after the cell death (Evert et al., 2006; Skulachev et al., 2009).

Occasionally, we noticed an accumulation of the fluorescent material at the lumen/Gn level in the kink-band region, as shown in Fig. S1, and irregular interruptions of the fluorescence signal in this layer along the fibre length, which can be attributed to a localised reduced thickness of the Gn cell wall or a localised modification of the composition that can lead to a lower fluorescence emission. Interestingly it is possible to note that even this innermost layer is deviated following the kink-band.

These images reported in Fig.4 demonstrate the continuity of the lumen along the kink-band area and allow the detection of darker areas, with less SHG response, throughout the fibre thickness. This finding demonstrates that the kink-band is not only a volumetric and localised geometric defect in the fibre periphery but in the entire volume of the fibre, including the $G$ and the Gn layers.

In order to evaluate the MFA values in the kink-band regions, Figure 5 shows a focus of SHG analysis in the bundle and one of the elementary fibres already illustrated in Fig.4, both 
mounded in water environment; Fig 5.a and b correspond to TA and TB kink-bands, respectively.

Figure 5

MFA values are generally included between 0 and $10^{\circ}$ in defect-free areas (Melelli et al., 2020); here, with this complementary study, we observed that stronger deviations exist in kink-band regions but they are mainly not an increase of the helix angle of the microfibrils to the fibre axis but rather an additional radial angular offset (Fig. 5). Nevertheless, in connection with the literature, we will denote MFA the whole microfibrils angle between the fibre longitudinal axis and the macrofibrils orientation. The MFA was manually estimated to range from $6^{\circ}$ to $47^{\circ}$ and $4^{\circ}$ to $17^{\circ}$ and for type A (Fig 5.a) and type B kink-bands (Fig 5.b), respectively. These values are well correlated with the MFA reported by Thygesen et al. (2013) who examined hemp kinkbands through Raman polarisation. Although the lack of spatial resolution of the SHG microscopy may lead to misinterpretation, it allows the in-situ investigation of the local MFA, as the macrofibrils are clearly visible in the acquired images. In contrast, when the MFA is measured using the X-ray scattering diffraction technique, various limitations are encountered: i. the values are deduced by fitting the signals, ii. they are a mean of the whole fibre bundle and iii. MFA $<8-9^{\circ}$ cannot be measured without specific calibration. These limits can be overcome using the SHG microscopy as the MFA is directly measured.

In this study, a variability was noted between the angles of deviation in the large (TA) and small (TB) kink-bands, influencing the entire macrofibrillar network. In the type B kink-band, the deviation angle of the macrofibrils is lower, and the network is still ordered even inside the kink-band. On the contrary, the type A kink-band exhibits dark areas in which the network is not detected even when the fibre is mounted in water, possibly linked to the presence of detached macrofibrils that create cavities as previously evidenced by SEM observations. 
3.3. AFM-PF-QNM mapping to explore mechanical properties and topography of kink-bands areas

The micro-mechanical properties of the kink-band are a key aspect. Nevertheless, although several papers suggest that kink-bands are the weakest point, structurally or mechanically speaking, relevant information regarding the mechanical behaviour of this region compared to that in the defect-free areas of the same fibre is not available in the literature.

The AFM PF-QNM technique, and other very similar fast force-distance curves modes, can be used to evaluate the indentation modulus of plant cell walls at the micro and nanoscale levels (Arnould et al., 2017; Casdorff et al., 2017; Goudenhooft et al., 2018; Casdorff et al., 2018; Bourmaud et al., 2019a; Coste et al., 2020); however, to the best of our knowledge, until now, mechanical information pertaining to the kink-band areas of bast fibres has not been provided. Although the AFM technique has been applied in other fields to investigate kink-bands in collagen (Stylianou and Yova, 2013) and polymeric fibres (Hu et al., 2003), conventional AFM modes were applied and do not provide mechanical information.

Figure 6 shows two maps of indentation modulus of kink-band regions in a bundle consisting of at least two single flax fibres (Fig.6.a) and in an elementary fibre (Fig.6.b) respectively. In the bundle, three homogenous areas were selected in the kink-band, indicated by blue squares, and these areas were considered to calculate the mean indentation modulus inside the kink-band region. In addition, four areas (black squares) were selected to calculate the mean indentation modulus in a homogeneous area without defects. Similar work was performed in the single fibre kink-band, by selecting two areas inside the kink-band (red squares) and three areas outside (black squares). All the regions of interest were carefully selected in the areas of the image that showed no evidence of accumulated material or roughness generated during the sample preparation, especially during the cutting step with the ultramicrotome.

Figure 6 
A small difference is observed in the indentation modulus calculated on the defect-free areas of the two fibre elements, around 6.2 GPa for the bundle and 7.3 GPa for the elementary fibre, that could be due to a difference in the MFA or the cutting angle. In all cases, indentation modulus distributions of the kink-band region and the region without defects are similar, with values of about 6.8-7.0 GPa for the kink-band areas. The small difference likely occurs as the topography is considerably more inhomogeneous inside the kink-band and affects the values of the indentation moduli. If two neighbouring points with the same indentation modulus have a marked difference in the topography at the scale of the tip radius, their indentation moduli are expected to be underestimated or overestimated, due to an erroneous implicitly used contact area in the indentation stiffness formulae (Stan and Cook, 2008; Heinze et al., 2018). The fact that the indentation modulus is similar in all areas, while the apparent MFA measured by SHG is not the same, could be mainly explained by the fact that the measured surface is parallel to the microfibrils direction and their rotation in the kink-bands is in this plane.

Figure 7

In Fig.7.a, the topography of the bundle in Fig.6.a is reported and specific areas analysed in detail are indicated with white dashed squares. Fig. 7.b and Fig.7.c show the details of the area affected; the kink-band topography exhibits a particular morphology corresponding to a transition region, which involves depression of the cell wall alternated by a crest-like structure, as illustrated in the 3D topography (Fig.7.d) and indicated by a blue and red arrow respectively. Similar morphology was also observed in Fig.7.e and Fig.7.f, which show the topography and the 3D of the single fibre previously analysed in Fig.6.b.

This particular topography seems to be a specific feature of TA kink-bands. However, we cannot completely exclude the hypothesis that it could be attributed to a pull-out 
phenomenon that occurred when cutting the sample with the diamond knife due to the higher misalignment of the microfibril with the cutting direction.

Figure 8

The crest-depression structure can be correlated with the image of the bundle obtained using the SHG microscopy technique (Figure 8), in which certain folds are visible. In contrast to the SHG microscopy, which performs measurements within the core of the fibre, AFM measurements are performed at the surface of the fibre cut in two parts along its length, albeit above or below the lumen. We assume that the structures observed in the AFM likely resulted from the cutting of the folds observed in the SHG. The crests in the AFM could correspond to the area with the most misaligned macrofibrillar network in the SHG.

\subsection{Kink-band areas, a complex and sensitive structure}

Through this work, a set of structural and mechanical information was obtained, using three different techniques. In TA kink-band areas, heterogeneous zones, located in the transition zones between kink-band and defect-free areas were highlighted by SEM (Fig.3.j) and confirmed with SHG and AFM observations. In these regions, there is no or very poor SHG emission signal (Fig.8), indicating a more disordered structure. These observations are in line with literature assessments and in particular with the hypothesis of Zhang et al. (Zhang et al., 2015) where the authors noted that the kink-band region included a main cavity consisting of several voids assembled and separated by membranes, also associated with the presence of small pores regrouped in the area close to the kink. By using AFM, it is possible to explore further these defect regions, inside the kink-band zone. According to this objective, Figure 9.a shows the same bundle of Fig.6, with the areas analysed in detail represented by white dashed squares. In Figs.9.b, c and d, inhomogeneities at the transition zones located at the limit between the kink-band the defect- 
free areas are clearly highlighted. Macrofibrils have a highly ordered structure in the depression regions, even though they are deflected with a well-defined angle; however, at the top of the crest, the macrofibrillar network appears less ordered, and it is impossible to distinguish the single macrofibrils from each other (Figs.9.b, e and f). The cavities that alternate with the crest-like inhomogeneities may suggest a weaker point at which the stress during tensile load may be accumulated until failure (Dhakal and Sain, 2019). The observations made here on a TA kink-band contrast with the much smaller defects and cavities observed on TB kink-band (Fig.S2). This observation can support the hypothesis of Aslan et al. (2011): the large kink-bands are likely the areas where failures begin, because they exhibit the most considerable heterogeneities. The indentation modulus maps shown in Figs.9.b, c and d indicate that, in some cases, a discontinuity may occur between macrofibrils, which may result in a break with the lines having a lower indentation modulus. In the topography, these lines, which appear as a detachment between the macrofibrils bundles, correspond to small depression regions, as observed in the SEM micrographs presented in Fig.3.i and $\mathrm{j}$.

Therefore, the kink-band areas show more or less disordered structures depending on their morphology, with sometimes marked cavities resulting from the deformations at the origin of the formation of kink-bands; the latter also lead to very significant changes in the local MFA values as shown by SEM and SHG (Fig.3.e and Fig.5). Nevertheless, cell wall mechanical properties are little affected, whatever the considered area and the kink-band type (Fig.6 and Fig.S2). In the present work, we measured $G$ transverse indentation modulus ranged from 6.2 to $7.3 \mathrm{GPa}$, which includes both kink-band and defect-free areas; these values are significantly lower than local longitudinal indentation modulus obtained by Arnould et al. by using the AFM in PF-QNM mode, confirming the highly anisotropic structure of fibres (Bourmaud and Baley, 2009). Here, the AFM PF-QNM measurements can be used to directly determine the transverse indentation modulus of flax cell walls. Our results are well correlated with the direct measurements obtained by nanoindentation on wood (Eder et al., 2013) or sisal and hemp (Bourmaud and Baley, 2009) but are more reliable due to the large 
number of measurement points (between 11,800 and 20,000 points for each image) and the method of sample preparation, which allows the direct testing of the cell wall. Considering wood cell walls, and by tilting the fibres to estimate their different stiffness tensor components, Jäger et al. (Jäger et al., 2011) calculated the transverse indentation modulus of spruce wood cell wall to be $6.02 \pm 0.38 \mathrm{GPa}$, which is in accordance with the presented values, given the difference in the chemical composition and MFA.

Therefore, the kink-band areas exhibit (almost) unchanged $\mathrm{G}$ cell wall mechanical performance compared to defect-free zones but an altered ultrastructure, whether in terms of porosities or MFA changes, suggesting that they appear after the cell wall structuration and explaining the differences in mechanical behaviour observed on fibres with a large number of defects ( Baley, 2004; Thygesen et al., 2007); the cavities can also lead to easy-going breaks, as we have seen after cryofracture (Fig.3.h), the ruptures occurring preferentially in the kink-band areas, this is also the case when flax fibres are mixed with a thermoplastic matrix (Le Duc et al., 2011).

3.5. Three investigative techniques but also three scales of measurement; what are the cell wall elements measured?

The use of three different techniques, with different resolutions, raises questions about the nature of the objects measured in each case. Several models for the ultrastructure of plant fibres have been reported in the literature. However, conclusions are sometimes contradictory when describing the hierarchy from a fibril to the fibre bundle in terms of the elementary unit with the relative diameter (Niklas, 2004; Zhu et al., 2014; Li et al., 2018) and when describing the ultrastructure of a single elementary fibre and the cellulose microfibril orientation inside the layers (Roland et al., 1995; Biagiotti et al., 2004; Domenges and Charlet, 2010; Bourmaud et al., 2018; Baley et al., 2018).

In the classical attribution currently used in biology (Chinga-Carrasco, 2011), several glucan chains (18-40 units) constitute a single elementary fibril of crystalline cellulose, and several elementary fibrils are regrouped in a structure known as a microfibril, which has a diameter of 
a few nanometres (Meier, 1962; Frey-Wyssling, 1968; Blackwell and Kolpak, 1975; Azizi Samir et al., 2005). Despite the disagreement pertaining to the smallest unitary fibril structure and the terminology (for instance, the term "elementary fibril" is often used to indicate a microfibril), it is generally accepted that microfibrils have a diameter ranging from 2 to $4 \mathrm{~nm}$ (Donaldson, 2007; Lyczakowski et al., 2019; Bourmaud et al., 2019b), although certain researchers reported on microfibrils having a diameter of approximately $20 \mathrm{~nm}$ for certain plants (Azizi Samir et al., 2005; Summerscales et al., 2010). Nevertheless, this aspect is irrelevant for our results, and furthering this debate is beyond the scope of this work. In contrast, it has been confirmed that several microfibrils are grouped to form bundles named macrofibrils (or mesofibrils). These structures have been examined using several analytical techniques such as AFM, SEM or transmission electron microscopy (TEM) and it has been noted they have a diameter ranging from 14 to 200 nm (Fahlén and Salmén, 2003; Balnois et al., 2007; Donaldson, 2007).

Furthermore, the SEM, SHG microscopy and AFM techniques can help in understanding the hierarchy between the micro/macro fibrils and the relationship with the MFA. Figure 10 shows the comparison between the three techniques used to investigate the thickness of the micro/macrofibrils, and the corresponding results are shown in the graphics on the right. The SEM microscopy can resolve the elements at the nanometre scale, and a single fibrillar unit (profile in white) has a thickness of approximately $150 \mathrm{~nm}$, typical of macrofibrils.

\section{Figure 10}

In contrast, the SHG microscopy exhibits bands with a thickness of approximately $1.0 \mu \mathrm{m}$, which is extremely large to be assigned to a single macrofibril. However, since the SHG response depends on the order and geometry of the structure, the signal is likely the result of a whole separate bundle of macrofibrils. 
The AFM has the highest resolution compared to the other techniques used in this work and can correctly resolve an object of a few nanometres (Fahlén and Salmén, 2003; Balnois et al., 2007; Raj et al., 2009). The smallest fibril structure examined in this study has a size range of 40-60 $\mathrm{nm}$ (Figs.10 and S3, respectively); however, in the literature, the microfibrils have been defined to have a diameter of approximately $4-10 \mathrm{~nm}$. In addition, the tip of the AFM probe has a finite dimension that leads to the well-known 'dilation or convolution effect' (Hanley et al., 1992; Thimm et al., 2000), i.e., the size of an isolated object measured by AFM is enlarged by the size of the tip diameter. Moreover, the microfibrils may be embedded or coated with a slight layer of the cell wall matrix, which makes them appear larger than they are. In our case, the tip radius ranges from 40 and $55 \mathrm{~nm}$; consequently, the size of the objects measured in this work is comparable to that of the microfibrils, in line with the findings of Donaldson (2007). In particular, Donaldson reported that the smallest microfibril found in wood had a diameter of $14 \mathrm{~nm}$; the measurements were performed using field emission scanning electron microscope (FESEM), which, in this case, can resolve objects of a few nanometres, similar to the AFM technique.

Figure 11

Thus, AFM confirms here its potential use as a powerful structural investigation tool; to illustrate, in Fig.11.a, 6 microfibrils are group together to form a single macrofibril visible from the drawn profile traced (Fig.11.b). The microfibrils, as well as the associated macrofibril, are well distinguishable on the image of topography and corresponding profile.

\section{Conclusions}

In the present work, cutting-edge techniques, such as the atomic force microscopy in peak force mode (AFM PF-QNM) and the second harmonic generation microscopy (SHG), were 
combined to study structural and mechanical properties of flax fibres kink-bands regions. SEM analysis was also performed to consolidate and bring additional understanding elements. The main conclusions of this cross study are the followings:

- SEM and AFM investigations evidenced the presence of cavities in large kink-bands which was supported by a low SHG signal, proving a deficiency of crystalline cellulose or a simply more disordered network in these specific zones, after the formation of the kinkband.

- In kink-band areas, strong deviations of MFA were visually highlighted with the three techniques, SEM exhibited significant MFA evolution in G layer and these observations were quantified through SHG imaging; interestingly these changes were more pronounced in TA kink-bands $\left(6-47^{\circ}\right)$ compared to TB ones $\left(4-17^{\circ}\right)$.

- Despite its deviation, a continuity of the lumen also in areas affected by kink-bands was demonstrated through SHG and AFM observations, which suggest that the kink-band involves also the inner structure of the cell.

- Deep mechanical characterization of kink-band transverse stiffness was addressed using the AFM in PF-QNM mode; no substantial differences were observed between the kinkband and defect-free regions.

- This original combination of techniques may give rise to a debate on the size and nature of the objects measured which is different according to the tool used, from nanofibrils through AFM to aggregates of macrofibrils by using multiphoton microscopy.

The elements provided in this work contribute to a better knowledge of these areas of defects; using a crossover approach, relevant information was obtained on the MFA in this specific zone; more than just the cell wall mechanical properties, weakness of kink-band areas is attributed to defects in local structure, inducing an easier rupture under stress. The present work does not pretend to be exhaustive. In future work, it would be interesting to widen the panel of defects studied by focusing on their origins. Indeed, environmental 
conditions, abiotic stress during growth or the process of fibre extraction, can also influence the shape and morphology of the kink-band region.

\section{Acknowledgements}

The authors wish to acknowledge the funding provided by the INTERREG IV Cross Channel programme through the FLOWER project. Additionally, the authors wish to thank SOLEIL Synchrotron for funding the 99180266 in-house proposal.

\section{References}

Andersons, J., Porike, E., Spārninš, E., 2009a. The effect of mechanical defects on the strength distribution of elementary flax fibres. Compos. Sci. Technol. 69, 2152-2157. https://doi.org/10.1016/j.compscitech.2009.05.010

Andersons, J., Spārninš, E., Porike, E., 2009b. Strength and Damage of Elementary Flax Fibers Extracted from Tow and Long Line Flax. J. Compos. Mater. 43, 2653-2664. https://doi.org/10.1177/0021998309345035

Arnould, O., Siniscalco, D., Bourmaud, A., Le Duigou, A., Baley, C., 2017. Better insight into the nanomechanical properties of flax fibre cell walls. Ind. Crops. Prod. 97, 224-228. https://doi.org/10.1016/j.indcrop.2016.12.020

Aslan, M., Chinga-Carrasco, G., Sørensen, B.F., Madsen, B., 2011. Strength variability of single flax fibres. J. Mater. Sci. 46, 6344-6354. https://doi.org/10.1007/s10853-011-5581-x Astley, O.M., Donald, A.M., 2001. A Small-Angle X-ray Scattering Study of the Effect of Hydration on the Microstructure of Flax Fibers. Biomacromolecules 2, 672-680. https://doi.org/10.1021/bm005643| 
Azizi Samir, M.A.S., Alloin, F., Dufresne, A., 2005. Review of Recent Research into Cellulosic Whiskers, Their Properties and Their Application in Nanocomposite Field. Biomacromolecules 6, 612626. https://doi.org/10.1021/bm0493685

Baley, C., 2004. Influence of kink bands on the tensile strength of flax fibers. J. Mater. Sci. 39, 331334.

Baley, C., Goudenhooft, C., Gibaud, M., Bourmaud, A., 2018. Flax stems: from a specific architecture to an instructive model for bioinspired composite structures. Bioinspir. Biomim. 13, 026007. https://doi.org/10.1088/1748-3190/aaa6b7

Balnois, E., Busnel, F., Baley, C., Grohens, Y., 2007. An AFM study of the effect of chemical treatments on the surface microstructure and adhesion properties of flax fibres. Compos. Interfaces 14, 715-731. https://doi.org/10.1163/156855407782106537

Beaugrand, J., Guessasma, S., Maigret, J.-E., 2017. Damage mechanisms in defected natural fibers. Sci. Rep. 7, 1-7 https://doi.org/10.1038/s41598-017-14514-6

Benabou, L., 2008. Kink Band Formation in Wood Species Under Compressive Loading. Exp. Mech. 48, 647-656. https://doi.org/10.1007/s11340-007-9098-9

Biagiotti, J., Puglia, D., Kenny, J.M., 2004. A Review on Natural Fibre-Based Composites-Part I: Structure, Processing and Properties of Vegetable Fibres. J. Nat. Fibers 1, 37-68. https://doi.org/10.1300/J395v01n02_04

Blackwell, J., Kolpak, F.J., 1975. The Cellulose Microfibril as an Imperfect Array of Elementary Fibrils. Macromolecules 8, 322-326. https://doi.org/10.1021/ma60045a015

Bos, H., Donald, A., 1999. In situ ESEM study of the deformation of elementary flax fibres. J. Mater. Sci. 34, 3029-3034.

Bourmaud, A., Baley, C., 2009. Rigidity analysis of polypropylene/vegetal fibre composites after recycling. Polym. Degrad. Stabil. 94, 297-305. https://doi.org/10.1016/j.polymdegradstab.2008.12.010 
Bourmaud A, Morvan C, Bouali A, Placet V, Perré P, Baley C., 2013. Relationships between microfibrillar angle, mechanical properties and biochemical composition of flax fibers. Ind. Crops Prod. 44, 343-351. doi:http://dx.doi.org/10.1016/j.indcrop.2012.11.031.

Bourmaud, A., Beaugrand, J., Shah, D.U., Placet, V., Baley, C., 2018. Towards the design of highperformance plant fibre composites. Prog. Mater. Sci. 97, 347-408. https://doi.org/10.1016/j.pmatsci.2018.05.005

Bourmaud, A., Mérotte, J., Siniscalco, D., Le Gall, M., Gager, V., Le Duigou, A., Pierre, F., Behlouli, K., Arnould, O., Beaugrand, J., Baley, C., 2019a. Main criteria of sustainable natural fibre for efficient unidirectional biocomposites. Compos. Part A: Appl. Sci. Manuf. 124, 105504. https://doi.org/10.1016/j.compositesa.2019.105504

Bourmaud, A., Siniscalco, D., Foucat, L., Goudenhooft, C., Falourd, X., Pontoire, B., Arnould, O., Beaugrand, J., Baley, C., 2019b. Evolution of flax cell wall ultrastructure and mechanical properties during the retting step. Carbohydr. Polym. 206, 48-56.

https://doi.org/10.1016/j.carbpol.2018.10.065

Casdorff, K., Keplinger, T., Burgert, I., 2017. Nano-mechanical characterization of the wood cell wall by AFM studies: comparison between AC- and QI ${ }^{\mathrm{TM}}$ mode. Plant Methods 13, 1-9. https://doi.org/10.1186/s13007-017-0211-5

Casdorff, K., Keplinger, T., Rüggeberg, M., Burgert, I., 2018. A close-up view of the wood cell wall ultrastructure and its mechanics at different cutting angles by atomic force microscopy. Planta 247, 1123-1132. https://doi.org/10.1007/s00425-018-2850-9

Célino, A., Fréour, S., Jacquemin, F., Casari, P., 2014a. The hygroscopic behavior of plant fibers: a review. Front. Chem. 1, 1-12 https://doi.org/10.3389/fchem.2013.00043

Célino, A., Gonçalves, O., Jacquemin, F., Fréour, S., 2014b. Utilisation de la spectrométrie infrarouge pour une quantification rapide du taux d'humidité dans des fibres végétales. Rev. des compos. et des mater. av. 24, 81-95. https://doi.org/10.3166/rcma.24.81-95 
Chinga-Carrasco, G., 2011. Cellulose fibres, nanofibrils and microfibrils: The morphological sequence of MFC components from a plant physiology and fibre technology point of view. Nanoscale Res. Lett. 6, 417. https://doi.org/10.1186/1556-276X-6-417

Clair, B., Déjardin, A., Pilate, G., Alméras, T., 2018. Is the G-Layer a Tertiary Cell Wall?

Front Plant Sci. 9, 623. doi:10.3389/fpls.2018.00623

Coste, R., Pernes, M., Tetard, L., Molinari, M., Chabbert, B., 2020. Effect of the Interplay of Composition and Environmental Humidity on the Nanomechanical Properties of Hemp Fibers. ACS Sustain. Chem. Eng. 8, 6381-6390. https://doi.org/10.1021/acssuschemeng.0c00566

Coste, R., Soliman, M., Bercu, N.B., Potiron, S., Lasri, K., Aguié-Béghin, V., Tetard, L., Chabbert, B., Molinari, M., 2021. Unveiling the impact of embedding resins on the physicochemical traits of wood cell walls with subcellular functional probing. Compos. Sci. Technol. 201, 108485. https://doi.org/10.1016/j.compscitech.2020.108485

Dai, D., Fan, M., 2011. Investigation of the dislocation of natural fibres by Fourier-transform infrared spectroscopy. Vib. Spectrosc. 55, 300-306. https://doi.org/10.1016/j.vibspec.2010.12.009

Davies, G., Bruce, D., 1998. Effect of Environmental Relative Humidity and Damage on the Tensile Properties of Flax and Nettle Fibers. Text. Res. J. 68, 623-629.

Deyholos, M.K., Potter, S., 2014. Engineering bast fiber feedstocks for use in composite materials. Biocatal. Agric. Biotechnol. 3, 53-57. https://doi.org/10.1016/j.bcab.2013.09.001

Dhakal, H.N., Sain, M., 2019. Enhancement of Mechanical Properties of Flax-Epoxy Composite with Carbon Fibre Hybridisation for Lightweight Applications. Materials 13, 109. https://doi.org/10.3390/ma13010109

Domenges, B., Charlet, K., 2010. Direct Insights on Flax Fiber Structure by Focused Ion Beam Microscopy. Microsc. Microanal. 16, 175-182. https://doi.org/10.1017/S1431927609991292 
Donaldson, L., 2007. Cellulose microfibril aggregates and their size variation with cell wall type. Wood Sci. Technol. 41, 443-460. https://doi.org/10.1007/s00226-006-0121-6

Eder, M., Arnould, O., Dunlop, J.W.C., Hornatowska, J., Salmén, L., 2013. Experimental micromechanical characterisation of wood cell walls. Wood Sci. Technol. 47, 163-182. https://doi.org/10.1007/s00226-012-0515-6

Eder, M., Terziev, N., Daniel, G., Burgert, I., 2008. The effect of (induced) dislocations on the tensile properties of individual Norway spruce fibres. Holzforschung $62,77-81$. https://doi.org/10.1515/HF.2008.011

Evert, R.F., Esau, K., Esau, K., 2006. Esau's Plant anatomy: meristems, cells, and tissues of the plant body : their structure, function, and development. Wiley-Interscience, Hoboken, N.J.

Fahlén, J., Salmén, L., 2003. Cross-sectional structure of the secondary wall of wood fibers as affected by processing. J. Mater. Sci. 38, 119-126. https://doi.org/10.1023/A:1021174118468

Focher, B., Marzetti, A., Sharma, H.S.S., 1992. Changes in the structure and properties of flax fibre during processing, in: The Biology and Processing of Flax. H. S. S. Sharma and C. F. Van Sumere, M Publications, Belfast, pp. 329-342.

Frey-Wyssling, A., 1968. The ultrastructure of wood. Wood Sci. Technol. 2, 73-83.

Gorshkova T., Mikshina P., Petrova A., Chernova T., Mokshina N., Gorshkov O., 2018. Plants at Bodybuilding: Development of Plant "Muscles". In: Geitmann A, Gril J, editors. Plant Biomech. From Struct. to Funct. Mult. Scales, Cham: Springer International Publishing, pp 141-163. doi:10.1007/978-3-319-79099-2_7.

Goudenhooft, C., Siniscalco, D., Arnould, O., Bourmaud, A., Sire, O., Gorshkova, T., Baley, C., 2018. Investigation of the Mechanical Properties of Flax Cell Walls during Plant Development: The Relation between Performance and Cell Wall Structure. Fibers 6, 6. https://doi.org/10.3390/fib6010006 
Hanley, S., Giasson, J., Revol, J., Gray, D., 1992. Atomic force microscopy of cellulose microfibrils: comparison with transmission electron microscopy. Polym. J. 33, 4639-4642. https://doi.org/10.1016/0032-3861(92)90426-W

Heinze, K., Arnould, O., Delenne, J.-Y., Lullien-Pellerin, V., Ramonda, M., George, M., 2018. On the effect of local sample slope during modulus measurements by contact-resonance atomic force microscopy. Ultramicroscopy 194, 78-88. https://doi.org/10.1016/j.ultramic.2018.07.009

Hernandez-Estrada, A., Gusovius, H.-J., Müssig, J., Hughes, M., 2016. Assessing the susceptibility of hemp fibre to the formation of dislocations during processing. Ind. Crops Prod. 85, 382-388. https://doi.org/10.1016/j.indcrop.2016.01.006

Hu, W., Buzin, A., Lin, J.-S., Wunderlich, B., 2003. Annealing behavior of gel-spun polyethylene fibers at temperatures lower than needed for significant shrinkage. J. Polym. Sci. B Polym. Phys. 41, 403-417. https://doi.org/10.1002/polb.10372

Hughes, M., Sèbe, G., Hague, J., Hill, C., Spear, M., Mott, L., 2000. An investigation into the effects of micro-compressive defects on interphase behaviour in hemp-epoxy composites using halffringe photoelasticity. Compos. Interfaces 7, 13-29. https://doi.org/10.1163/156855400300183551

Jäger, A., Hofstetter, K., Buksnowitz, Ch., Gindl-Altmutter, W., Konnerth, J., 2011. Identification of stiffness tensor components of wood cell walls by means of nanoindentation. Compos. Part A AppL. Sci. Manuf. 42, 2101-2109. https://doi.org/10.1016/j.compositesa.2011.09.020

Khodayari, A., Van Vuure, A.W., Hirn, U., Seveno, D., 2020. Tensile behaviour of dislocated/crystalline cellulose fibrils at the nano scale. Carbohydr. Polym. 235, 115946. https://doi.org/10.1016/j.carbpol.2020.115946

Le Duc, A., Vergnes, B., Budtova, T., 2011. Polypropylene/natural fibres composites: Analysis of fibre dimensions after compounding and observations of fibre rupture by rheo-optics. C Compos. Part A AppL. Sci. Manuf. 42, 1727-1737. https://doi.org/10.1016/j.compositesa.2011.07.027 
Le Duigou, A., Davies, P., Baley, C., 2011. Environmental Impact Analysis of the Production of Flax Fibres to be Used as Composite Material Reinforcement. J. Biobased Mater. Bioenergy 5, 153-165. https://doi.org/10.1166/jbmb.2011.1116

Li, Y., Yi, X., Yu, T., Xian, G., 2018. An overview of structural-functional-integrated composites based on the hierarchical microstructures of plant fibers. Adv. Compos. Hybrid Mater. 1, 231-246. https://doi.org/10.1007/s42114-017-0020-3

Lyczakowski, J.J., Bourdon, M., Terrett, O.M., Helariutta, Y., Wightman, R., Dupree, P., 2019. Structural Imaging of Native Cryo-Preserved Secondary Cell Walls Reveals the Presence of Macrofibrils and Their Formation Requires Normal Cellulose, Lignin and Xylan Biosynthesis. Front. Plant Sci. 10, 1398. https://doi.org/10.3389/fpls.2019.01398

Madsen, B., Aslan, M., Lilholt, H., 2016. Fractographic observations of the microstructural characteristics of flax fibre composites. Compos. Sci. Technol. 123, 151-162. https://doi.org/10.1016/j.compscitech.2015.12.003

Madsen, B., Gamstedt, E.K., 2013. Wood versus Plant Fibers: Similarities and Differences in Composite Applications. Adv. Mater. Sci. Eng. 2013.

Meier, H., 1962. Chemical and morphological aspects of the fine structure of wood. Pure Appl. Chem. 5, 37-52. https://doi.org/10.1351/pac196205010037

Melelli, A., Jamme, F., Legland, D., Beaugrand, J., Bourmaud, A., 2020. Microfibril angle of elementary flax fibres investigated with polarised second harmonic generation microscopy. Ind. Crops Prod. 156, 112847. https://doi.org/10.1016/j.indcrop.2020.112847

Mohanty, A. K., Vivekanandhan, S., Pin, J.-M. \& Misra, M., 2018. Composites from renewable and sustainable resources: Challenges and innovations. Science. 362, 536-542. https://doi.org/10.1126/science.aat9072

Nakamura, K., Hatakeyama, T., Hatakeyama, H., 1983. Effect of Bound Water on Tensile Properties of Native Cellulose. Text. Res. J. 53, 682-688. https://doi.org/10.1177/004051758305301108 
Niklas, K.J., 2004. The Cell Walls that Bind the Tree of Life. BioScience 54, 831-841. https://doi.org/10.1641/0006-3568(2004)054[0831:TCWTBT]2.0.CO;2

Nilsson, T., Gustafsson, P.J., 2007. Influence of dislocations and plasticity on the tensile behaviour of flax and hemp fibres. Compos. Part A Appl. Sci. Manuf. 38, 1722-1728. https://doi.org/10.1016/j.compositesa.2007.01.018

Nodder, C.R., 1922. A Study of Flax and Kindred Fibres. J. Text. Inst. Proceedings and Abstracts 13, 161-171. https://doi.org/10.1080/03684504.1922.11673746

Nyholm, K., Ander, P., Bardage, S., Daniel, G., Science, W., 2001. Dislocations in pulp fibres - their origin, characteristics and importance - a review. Nord. Pulp Pap. Res. J. 16, 376-384.

Pil, L., Bensadoun, F., Pariset, J., Verpoest, I., 2016. Why are designers fascinated by flax and hemp fibre composites? Composites Part A: Applied Science and Manufacturing, Special Issue on Biocomposites 83, 193-205. https://doi.org/10.1016/j.compositesa.2015.11.004

Raj, G., Balnois, E., Baley, C., Grohens, Y., 2009. Adhesion Force Mapping of Raw and Treated Flax Fibres Using AFM Force-Volume. J. Scanning Probe Microsc. 4, 66-72. https://doi.org/10.1166/jspm.2009.1010

Roland, J.-C., Mosiniak, M., Roland, D., 1995. Dynamique du positionnement de la cellulose dans les parois des fibres textiles du lin (Linum usitatissimum). Acta Bot. Gall. 142, 463-484. https://doi.org/10.1080/12538078.1995.10515271

Skulachev, V.P., Anisimov, V.N., Antonenko, Y.N., Bakeeva, L.E., Chernyak, B.V., Erichev, V.P., Filenko, O.F., Kalinina, N.I., Kapelko, V.I., Kolosova, N.G., Kopnin, B.P., Korshunova, G.A., Lichinitser, M.R., Obukhova, L.A., Pasyukova, E.G., Pisarenko, O.I., Roginsky, V.A., Ruuge, E.K., Senin, I.I., Severina, I.I., Skulachev, M.V., Spivak, I.M., Tashlitsky, V.N., Tkachuk, V.A., Vyssokikh, M.Yu., Yaguzhinsky, L.S., Zorov, D.B., 2009. An attempt to prevent senescence: A mitochondrial approach. Biochim. Biophys. Acta (BBA)- Bioenerg. Mitochondrial Physiol. Pathol. 1787, 437461. https://doi.org/10.1016/j.bbabio.2008.12.008 
Sliseris, J., Yan, L., Kasal, B., 2016. Numerical modelling of flax short fibre reinforced and flax fibre fabric reinforced polymer composites. Compos. B. Eng. 89, 143-154. https://doi.org/10.1016/j.compositesb.2015.11.038

Stan, G., Cook, R.F., 2008. Mapping the elastic properties of granular Au films by contact resonance atomic force microscopy. Nanotechnology 19, 235701. https://doi.org/10.1088/0957$4484 / 19 / 23 / 235701$

Stylianou, A., Yova, D., 2013. Surface nanoscale imaging of collagen thin films by Atomic Force Microscopy. Mater. Sci. Eng. C 33, 2947-2957. https://doi.org/10.1016/j.msec.2013.03.029 Summerscales, J., Dissanayake, N.P.J., Virk, A.S., Hall, W., 2010. A review of bast fibres and their composites. Part 1 - Fibres as reinforcements. Compos. Part A Appl. Sci. Manuf. 41, 13291335. https://doi.org/10.1016/j.compositesa.2010.06.001

Thimm, J.C., Burritt, D.J., Ducker, W.A., Melton, L.D., 2000. Celery (Apium graveolens L.) parenchyma cell walls examined by atomic force microscopy: effect of dehydration on cellulose microfibrils. Planta 212, 25-32.

Thuault, A., Eve, S., Jouannot-Chesney, P., Bréard, J., Gomina, M., 2013. Interrelation Between the Variety and the Mechanical Properties of Flax Fibres. J. Biobased Mater. Bioenergy 7, 609618. https://doi.org/10.1166/jbmb.2013.1396

Thygesen, L.G., Asgharipour, M.R., 2008. The effects of growth and storage conditions on dislocations in hemp fibres. J. Mater. Sci. 43, 3670-3673. https://doi.org/10.1007/s10853-008-2587-0 Thygesen, L.G., Eder, M., Burgert, I., 2007. Dislocations in single hemp fibres-investigations into the relationship of structural distortions and tensile properties at the cell wall level. J. Mater. Sci. 42, 558-564. https://doi.org/10.1007/s10853-006-1113-5

Thygesen, L.G., Gierlinger, N., 2013. The molecular structure within dislocations in Cannabis sativa fibres studied by polarised Raman microspectroscopy. J. Struct. Biol. 182, 219-225. https://doi.org/10.1016/j.jsb.2013.03.010 
Toba, K., Yamamoto, H., Yoshida, M., 2013. Crystallization of cellulose microfibrils in wood cell wall by repeated dry-and-wet treatment, using X-ray diffraction technique. Cellulose 20, 633-643. https://doi.org/10.1007/s10570-012-9853-7

Wang, C., Wang, N., Liu, S., Choo-Simth, L.-P., Zhang, H., Zhi, Z., 2018. Investigation of Microfibril Angle of Flax Fibers Using X-Ray Diffraction and Scanning Electron Microscopy. J. Nat. Fibers 1-10. https://doi.org/10.1080/15440478.2018.1546639

Zeng, X., Mooney, S.J., Sturrock, C.J., 2015. Assessing the effect of fibre extraction processes on the strength of flax fibre reinforcement. Compos. Part A Appl. Sci. Manuf. 70, 1-7. https://doi.org/10.1016/j.compositesa.2014.12.004

Zhang, H., Sui, T., Thygesen, L.G., O’Brien, P., Korsunsky, A.M., 2015. Multi-modal Microscopy Characterisation of Nodal Markings in Flax Fibre, in: Proceedings of the World Congress on Engineering (WCE). London, U.K.

Zhu, H., Fang, Z., Preston, C., Li, Y., Hu, L., 2014. Transparent paper: fabrications, properties, and device applications. Energy Environ. Sci. 7, 269-287. https://doi.org/10.1039/C3EE43024C 


\section{Figure caption (main text)}

Figure 1. Schematic illustrating the sample preparation process for the AFM PF-QNM analysis. Several nearly aligned fibre bundles were embedded in agar resin in the transverse direction. The thickness of the steel disc and the mounted block are not scaled to present an enlarged view of the fibre bundles.

Figure 2. SEM micrographs of a flax fibre bundle $(a, b)$, in which all the fibres exhibit kinkbands located in the same area indicated by the red circle in (b); schematic representation (c) of a kink-band region in a bundle and (d) two different common types of kink-bands in a single fibre; the kink-band regions are indicated in red in (c) and (d).

Figure 3. SEM micrograph of a peeled elementary flax fibre (a) and magnified area showing details of the kink-band region (b); sub-details of this area are given on S1 layer (c), S1/G transition (d) zone and G layer structure (e). (h) is a SEM micrograph of a cryofractured fibre broken in the kink-band region, the lumen (white arrow) and the inner layers are clearly visible. The images (i, j) and (k, I) correspond to kink-bands type A (f) and B (g), respectively. It can be noted that the macrofibrils deviated and followed the shape of the kink-band in all the layers. In (j), certain macrofibrils were detached and less deviated than the surrounding macrofibrils, which led to the creation of cavities between them (indicated with the red arrows).

Figure 4. a) SHG microscopic imaging on two elementary flax fibres (a), mounted in air and water, with the signals collected considering the autofluorescence (merge channels of R460/60, T460/60, R550/88 and T550/88 TND) and SHG channels. The autofluorescence channels 460/60 (blue) and 550/88 (magenta) highlight the lumen coupled with the Gn layer, which is primarily responsible for the fluorescence signal, in the middle of the fibre; in contrast, the SHG channel shows the second harmonic emission due to the macrofibrils, and it can be noted that the MFA in the air and water environments is the same. The kink-band region, however, exhibits a higher SHG emission in water than that in air, due to the more orderly macrofibril network. In (b), a bundle of three fibres, two of which are in foreground, 
mounted in water was investigated at different depth. Kink-bands area show a different macrofibril orientation in the SHG channel, as well as the presence of a lumen+Gn layer in the autofluorescence channel.

Figure 5. SHG imaging of a bundles of three elementary flax fibres with two visible fibres in foreground (a) and a single elementary fibre (b) mounted in water where TA and TB kink-bands are identified, respectively. The MFA is approximately and manually estimated, following the macrofibrillar orientation and taking the fibre axis as a reference (blue arrow). The difference in terms of values between TA (a) and TB (b) is clearly observable.

Figure 6. Indentation moduli of a bundle consisting of at least two flax fibres (a) and of a single fibre (b) cut along their length and with a well-defined kink-band area; the blue and red squares represent the areas used to calculate the mean indentation modulus inside the defects, and the black squares represent the areas used to calculate the mean indentation modulus in the defect-free area. The graphic on the right represents the frequency distributions of the calculated indentation modulus in fibre and bundle. Approximately 7,000 and 24,800 measurements points were used for the kink-band region and defect-free areas, respectively. Figure 7. Topography images a) in the kink-band region of Fig.6.a with a focus on two areas (white dashed squares) in (b) and (c); d) 3D topography of the same area presented in (c) where a system of crest-depression is identified inside the kink-band region with red and blue arrows. e) Topography of the single fibre showed in Fig.6.b and f) the associated 3D topography where the same crest-depression system already noted in the bundle is observable (blue and red arrows).

Figure 8. SHG microscopic image of a kink-band in a bundle of flax fibres; the transition zone with a crest (red arrow) and depression (blue arrow) identified in the AFM topographic images is assumed to be in morphological contrast to the SHG analysis. Fibre bundle mounted in water.

Figure 9. Indentation modulus of several areas at different scales of the flax fibre bundle and kink-band area: a) whole bundle and areas investigated (white squares); b) and c) focus on one of the central defects and d) focus on the macrofibrils network; e) and f) other defects in 
the fibre on the right, which highlight a well-ordered network of macrofibrils in the transition zone.

Figure 10. SEM micrograph, SHG image and topographic map obtained using the AFM PFQNM. The images are compared to measure the fibril diameter. The grey value in the Y-axis of the SEM and SHG profiles indicates the brightness of the pixels in the image.

Figure 11. Topography of the area selected in Fig. 9.d after image processing for the local contrast to clearly highlight the bundles. The profile line (white) is shown in the graphic on the right, and 6 microfibrils can be identified (red arrows). The dotted lines indicate the edge of certain macrofibrils.

\section{Figure caption (supplementary material)}

Figure S1. SHG investigation; in the kink-band area, material accumulation from the Gn layer has occurred.

Figure S2. Topography and indentation modulus acquired using the AFM PF-QNM technique, by analysing another small kink-band region in the same fibre bundle as that examined in the study. The kink-band region is highlighted as a red line and through white arrows in the topography and indentation modulus map, respectively.

Figure S3. Topography of a small area selected from Fig. 8f; two profiles are considered to measure the microfibril diameter. 
Figure 1. Schematic for the sample preparation process for the AFM PF-QNM analysis. Several nearly aligned fibre bundles were embedded in agar resin in the transverse direction. The thickness of the steel disc and the mounted block are not presented in scale to present an enlarged view of the fibre bundles.

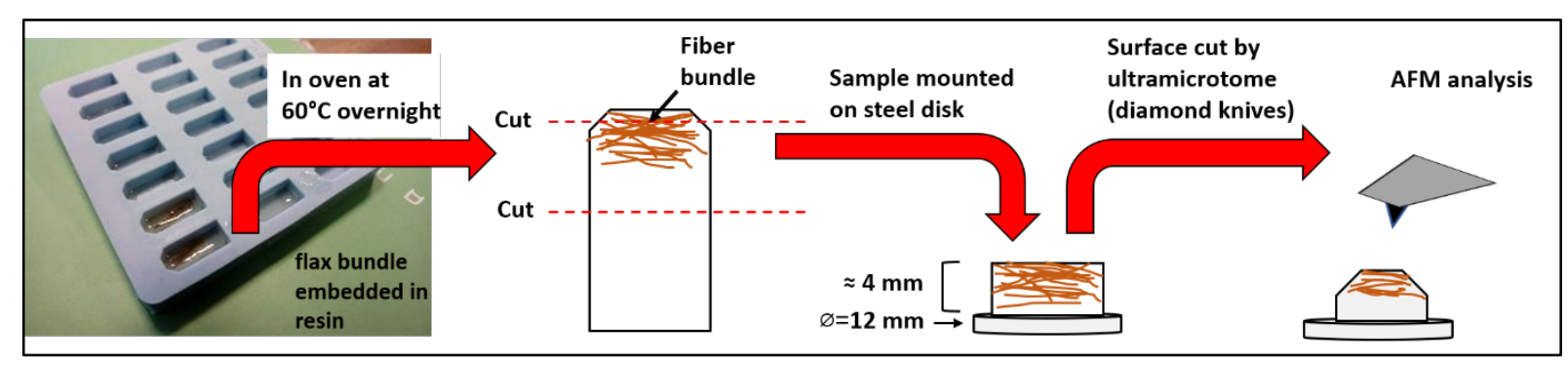


Figure 2. SEM micrographs of a flax fibre bundle $(a, b)$, in which all the fibres exhibit kinkbands located in the same area indicated by the red circle in (b); schematic representation (c) of a kink-band region in a bundle and (d) two different common types of kink-bands in a single fibre; the kink-band regions are indicated in red in (c) and (d).
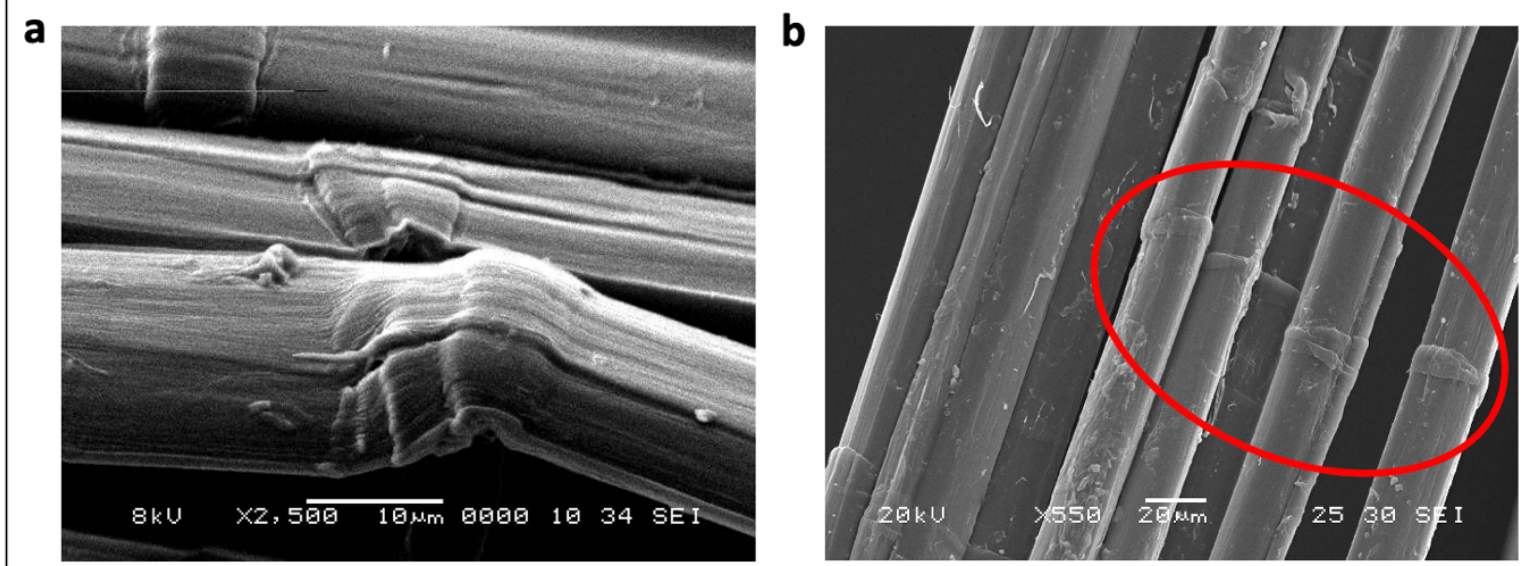

C

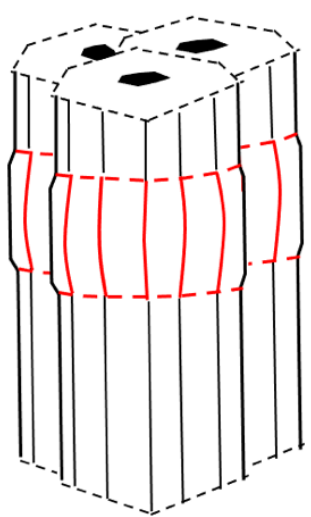

d

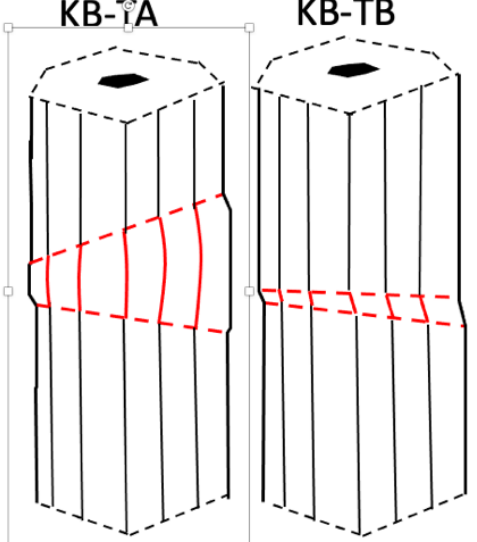


Figure 3. SEM micrograph of a peeled elementary flax fibre (a) and magnified area showing de- tails of the kink-band region (b); sub-details of this area are given on S1 layer (c), S1/G tran- sition (d) zone and G layer structure (e). (h) is an SEM micrograph of a cryofractured fibre broken in the kink-band region. The lumen (white arrow) and the inner layers are clearly visible. Images (i, j) and (k, I) correspond to kink-band types A (f) and B (g), respectively. It can be noted that the macrofibrils deviated and followed the shape of the kink-band in all the layers. In (j), certain macrofibrils were detached and less deviated than the surrounding macro- fibrils, which led to the creation of cavities be- tween them (indicated with the red arrows).

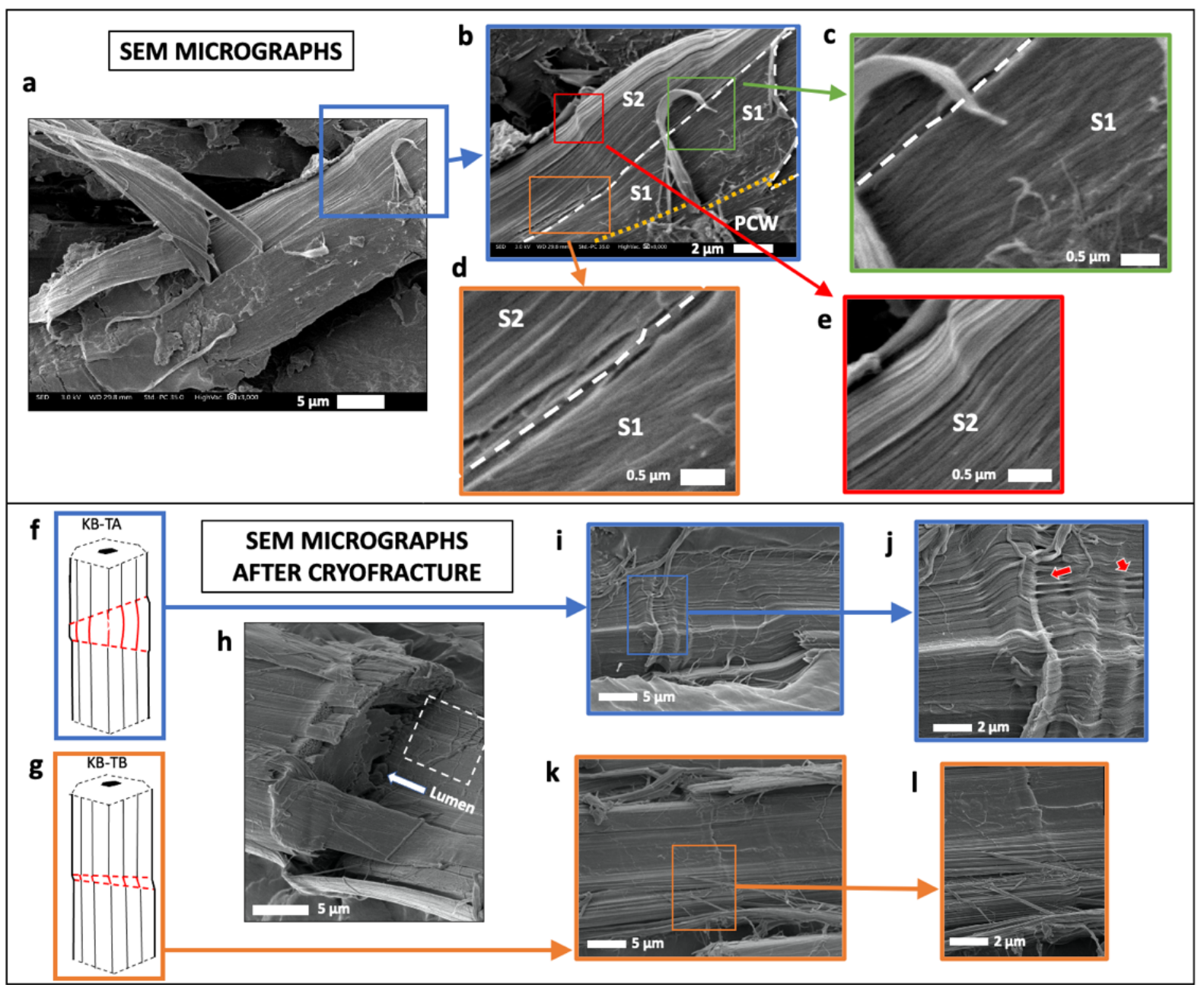


Figure 4. a) SHG microscopic imaging of two elementary flax fibres (a) mounted in air and water, with the signals collected considering the autofluorescence (merged channels of R460/60, T460/60, R550/88 and T550/88 TND) and SHG channels. The autofluorescence channels 460/ 60 (blue) and 550/88 (magenta) highlight the lumen coupled with the Gn layer, which is pri- marily responsible for the fluorescence signal, in the middle of the fibre; in contrast, the SHG channel shows the second harmonic emission due to the macrofibrils, and it can be noted that the MFA in the air and water environments is the same. The kink-band region, however, ex- hibits a higher SHG emission in water than in air due to the more orderly macrofibril network. In (b), a bundle of three fibres, two of which are in the foreground mounted in water, was investi- gated at different depths. Kink-band areas show a different macrofibril orientation in the SHG channel, as well as the presence of a lumen + Gn layer in the autofluorescence channel.

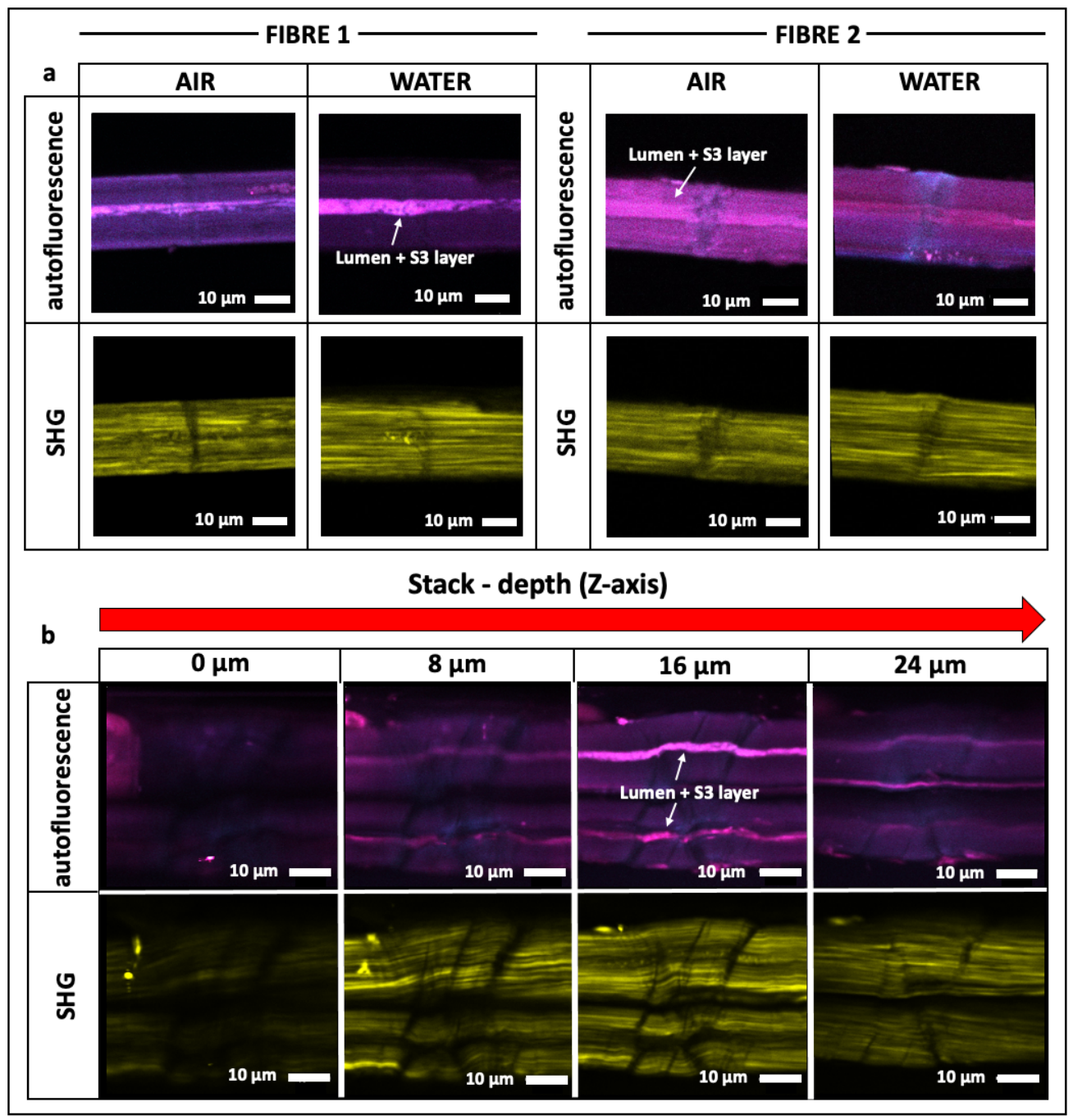


Figure 5. SHG imaging of bundles of three elementary flax fibres with two visible fibres in the foreground (a) and a single elementary fibre (b) mounted in water where TA and TB kink-bands are identified. The MFA is approximately and manually estimated, following the macrofibrillar orientation and taking the fibre axis as a reference (blue arrow). The difference in terms of values between TA (a) and TB (b) is clearly observable.

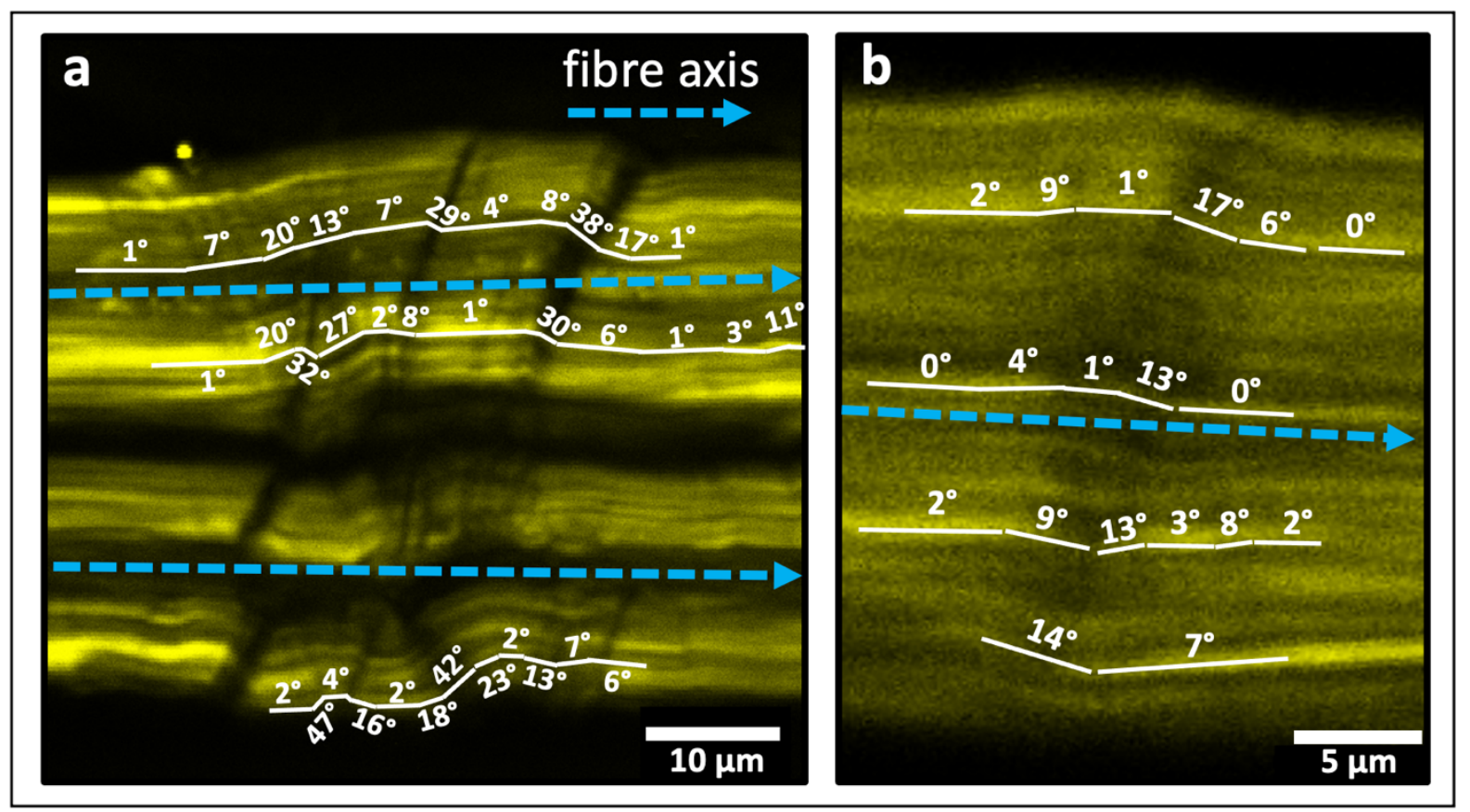


Figure 6. Indentation moduli of a bundle consist- ing of at least two flax fibres (a) and of a single fibre (b) cut along their length and with a well- defined kink-band area; the blue and red squares represent the areas used to calculate the mean indentation modulus inside the defects, and the black squares represent the areas used to calculate the mean indentation modulus in the defect-free area. The graphic on the right represents the frequency distributions of the calculated indentation modulus in the fibre and bundle. Approximately 7000 and 24,800 measurement points were used for the kink-band region and defect-free areas, respectively.

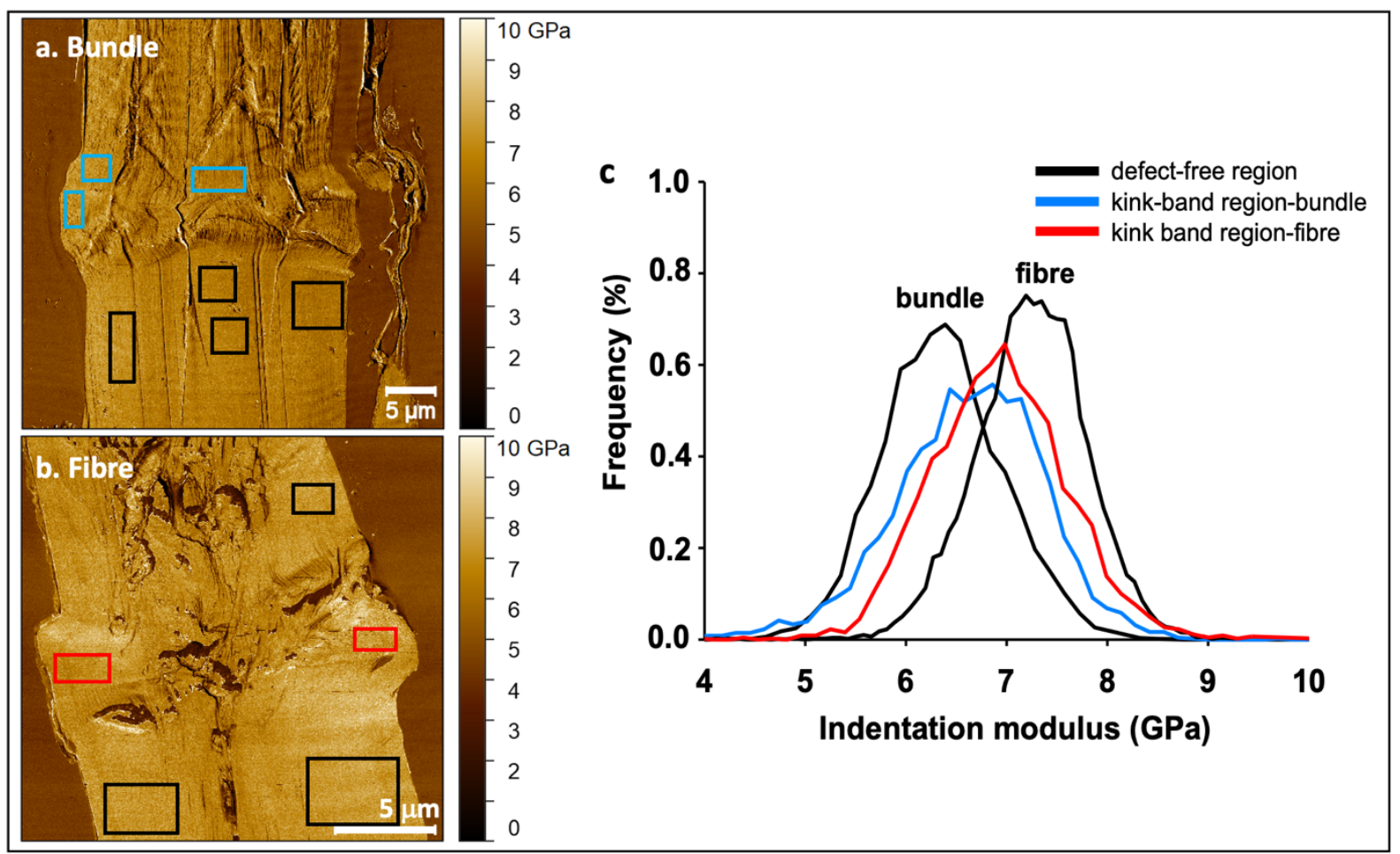


Figure 7. Topography images a) in the kink-band region of Fig. 6.a with a focus on two areas (white dashed squares) in (b) and (c); d) 3D topography of the same area presented in (c), where a system of crest depressions is identified inside the kink-band region with red and blue arrows. e) Topography of the single fibre shown in Fig. 6.b and f) the associated 3D topography where the same crest-depression system already noted in the bundle is observable (blue and red arrows).

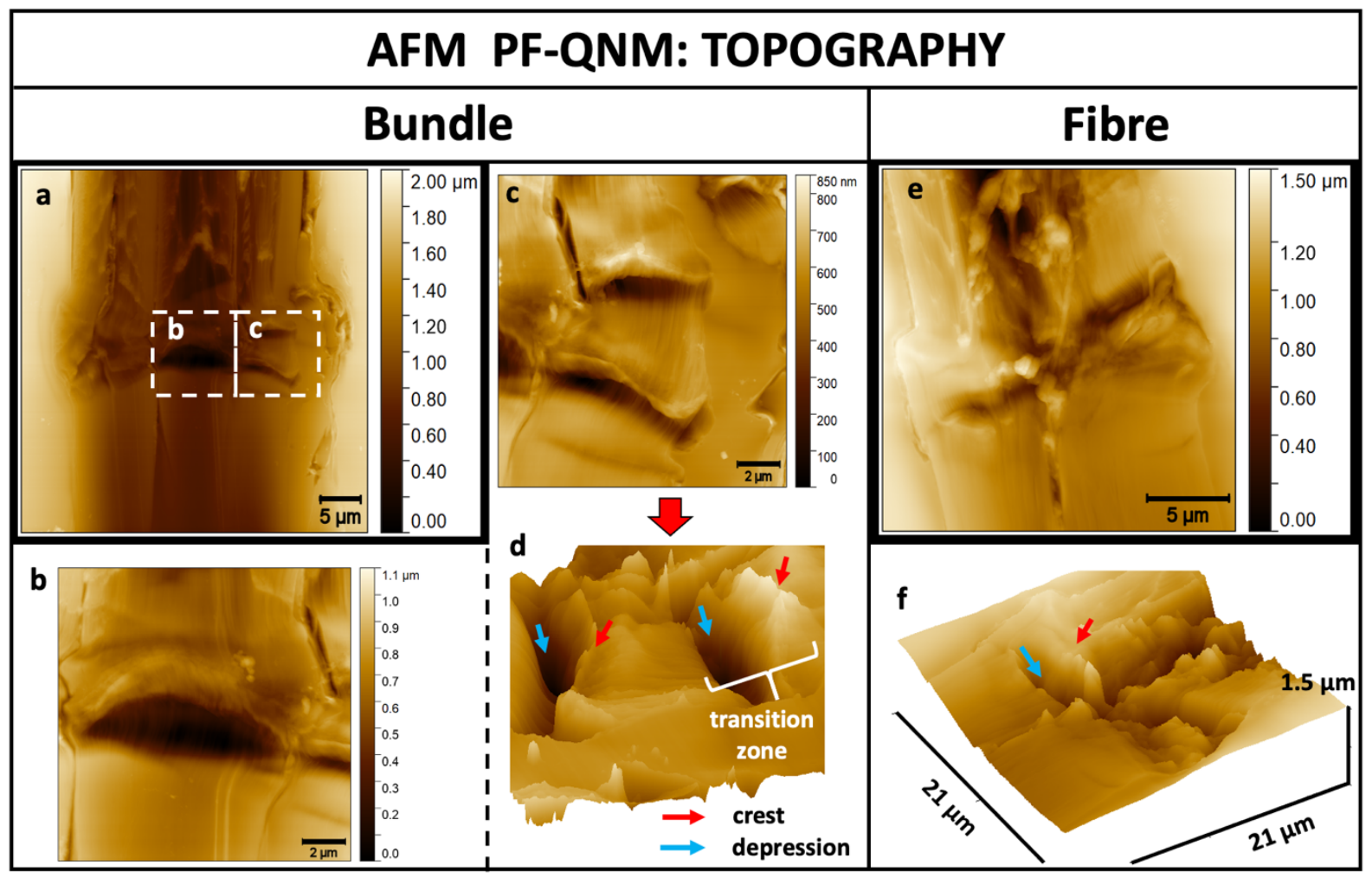


Figure 8. SHG microscopic image of a kink-band in a bundle of flax fibres; the junction region with a crest (red arrow) and depression (blue arrow) identified in the AFM topographic images is assumed to be in morphologically contrast to the SHG analysis. Fibre bundle mounted in water.

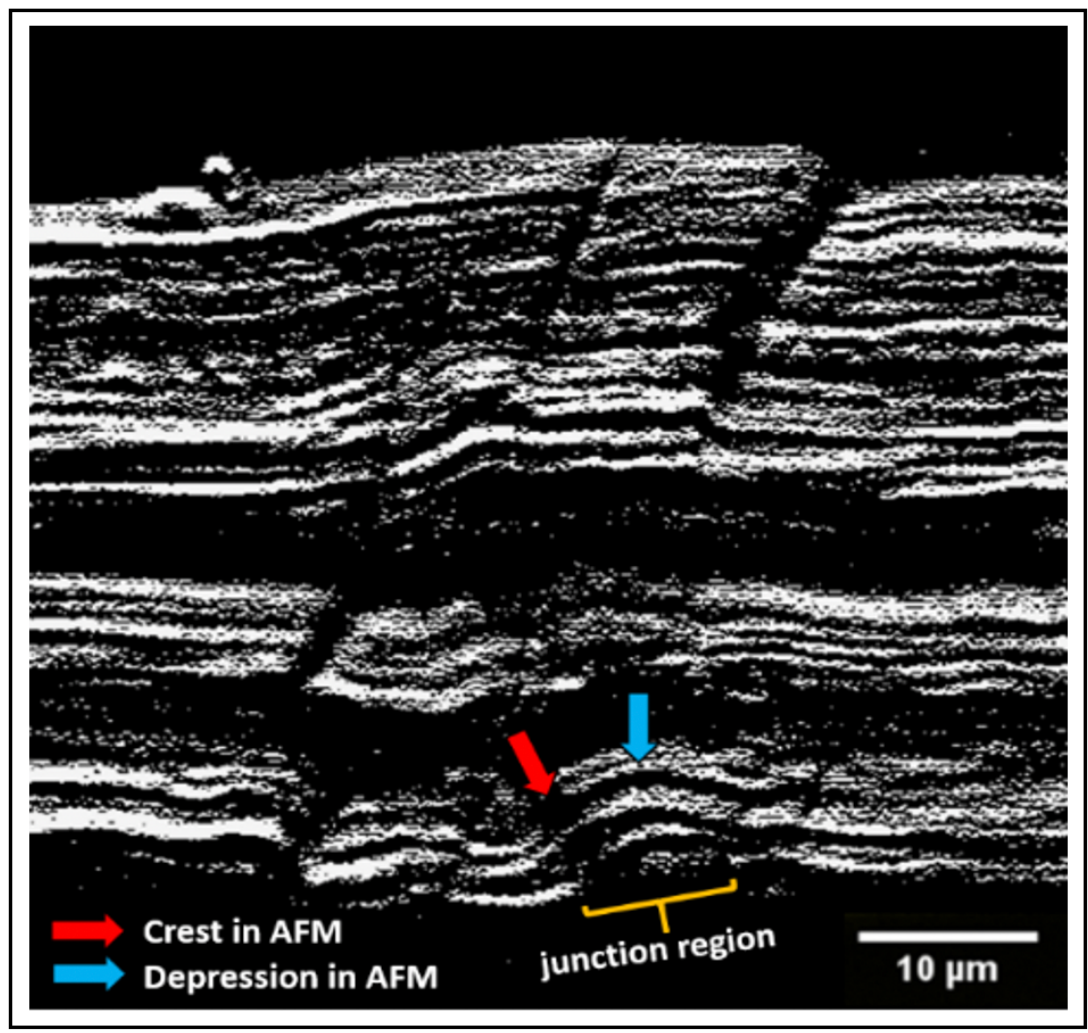


Figure 9. a) Indentation modulus of several areas at different scales of the flax fibre bundle and kink-band area a) whole bundle and areas investigated (white squares); b) and c) focus on one of the central defects of the second fibre on the right and d) focus on the macrofibrils network; e) and f) are other defects in the second fibre on the right, which highlight a wellordered network of macrofibrils in the junction region.

\section{AFM PF-QNM: INDENTATION MODULUS}

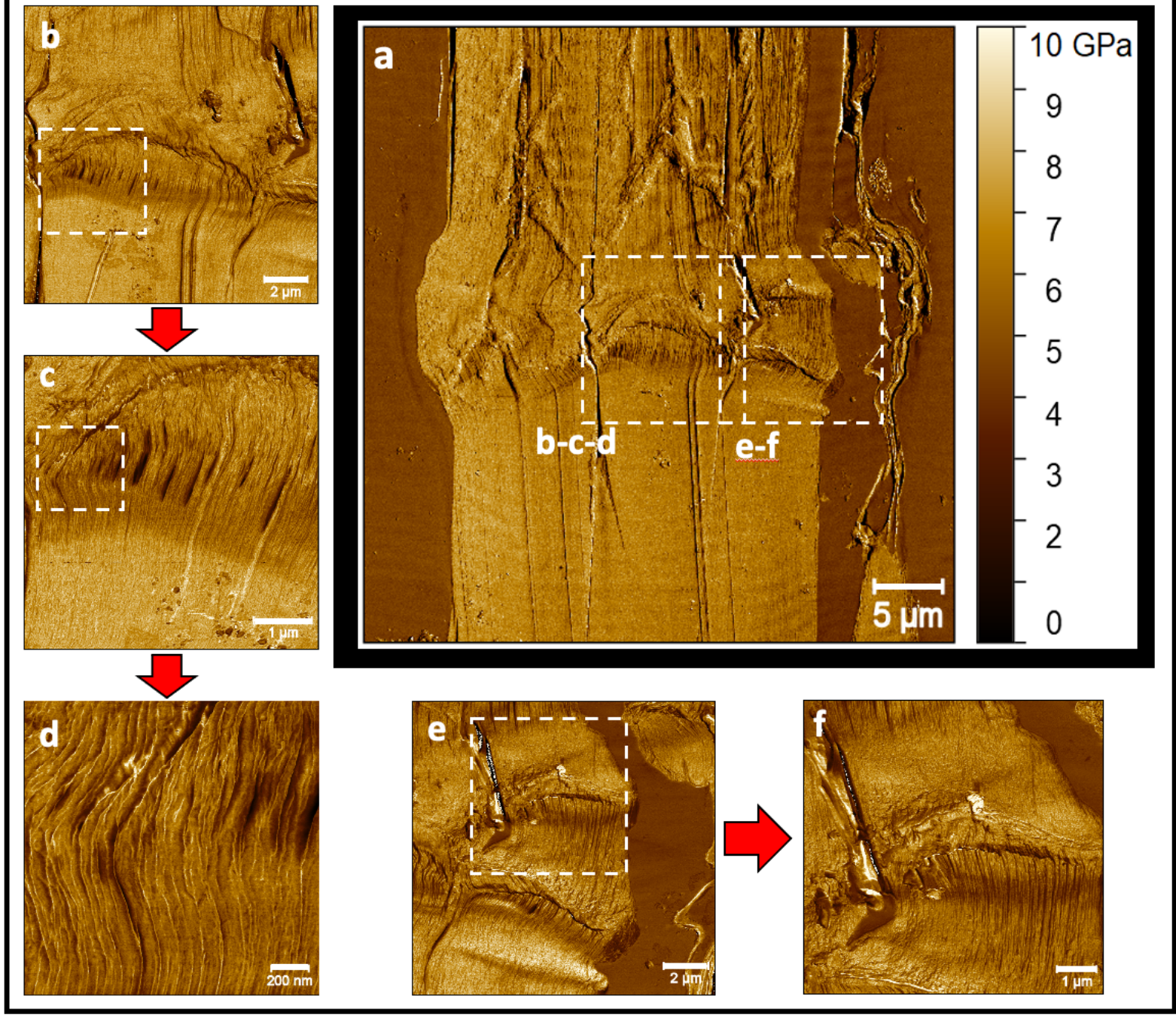


Figure 10. SEM micrograph, SHG image and topographic map obtained using the AFM PFQNM. The images are compared to measure the fibril diameter. The grey value in the Y-axis of the SEM and SHG profiles indicates the brightness of the pixels in the image.

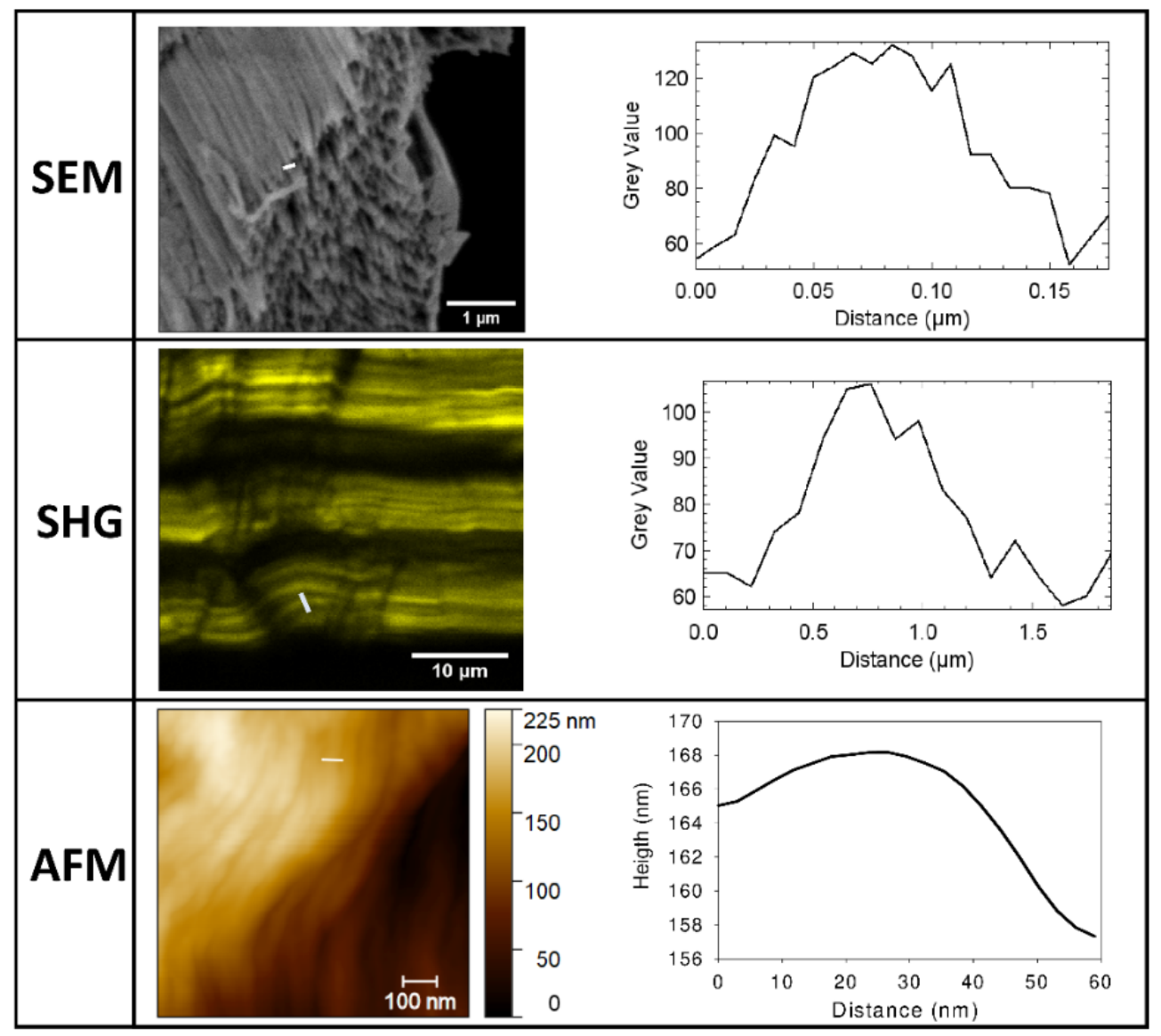


Figure 11. Topography of the area selected in Fig. 9.d after image processing for the local contrast to clearly highlight the bundles. The profile line (white) is shown in the graphic on the right, and 6 microfibrils can be identified (red arrows). The dotted lines indicate the edge of certain macrofibrils.

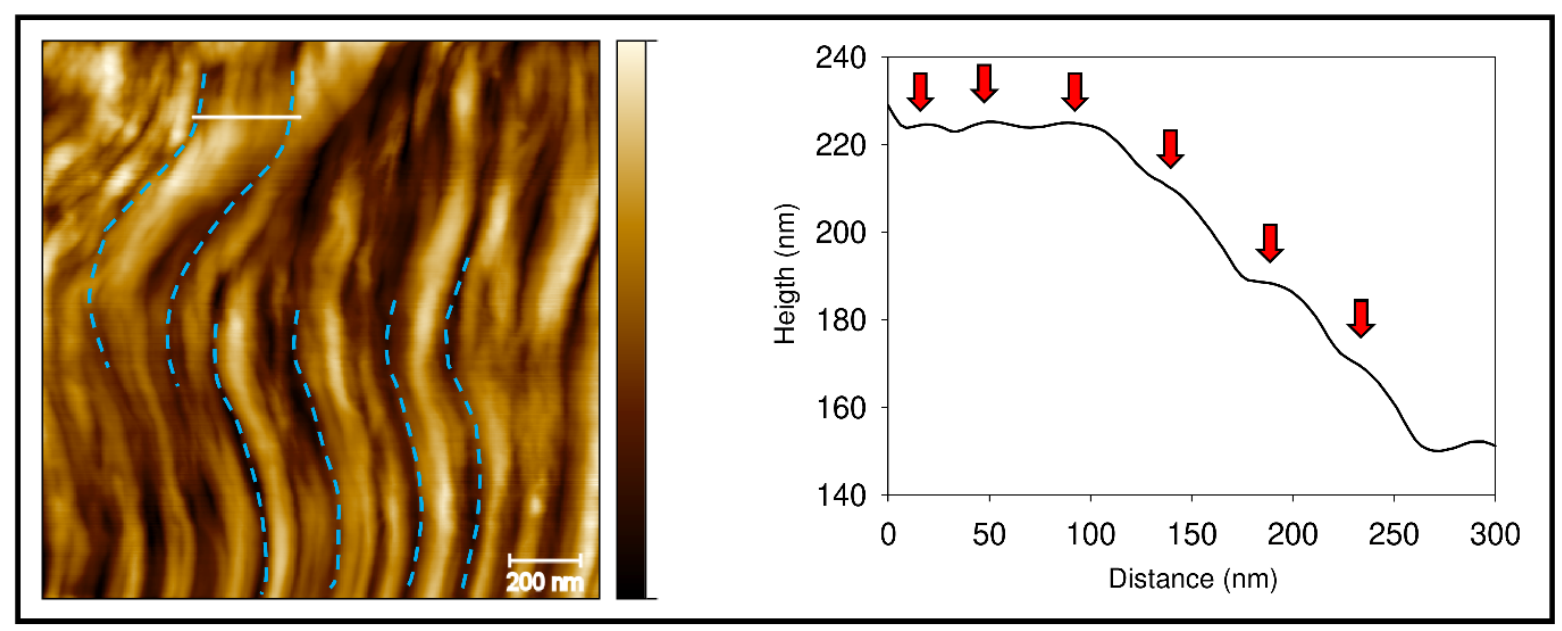

